NBER WORKING PAPER SERIES

\title{
FAMILY NETWORKS AND SCHOOL ENROLMENT: EVIDENCE FROM A RANDOMIZED SOCIAL EXPERIMENT
}

\author{
Manuela Angelucci \\ Giacomo De Giorgi \\ Marcos A. Rangel \\ Imran Rasul \\ Working Paper 14949 \\ http://www.nber.org/papers/w14949 \\ NATIONAL BUREAU OF ECONOMIC RESEARCH \\ 1050 Massachusetts Avenue \\ Cambridge, MA 02138 \\ May 2009
}

This research was supported by an IRB from the University of Chicago. The paper has been screened to ensure no confidential information is revealed. We thank Orazio Attanasio, Oriana Bandiera, Jere Behrman, Timothy Besley, Martina Bjorkman, Pedro Carneiro, Pierre-Andre Chiappori, Hilary Hoynes, Erik Lindqvist, Steve Machin, Ofer Malamud, Alan Manning, Guy Michaels, Debraj Ray, Jean-Marc Robin, Yoram Weiss, and seminar participants at Chicago, Columbia, IFS, INRA, LSE, Maryland, Northwestern, Stanford, Toulouse, UCL, and the NBER Children/Education Program Meeting (Boston 2008) for comments. All errors remain our own. The views expressed herein are those of the author(s) and do not necessarily reflect the views of the National Bureau of Economic Research.

NBER working papers are circulated for discussion and comment purposes. They have not been peerreviewed or been subject to the review by the NBER Board of Directors that accompanies official NBER publications.

(C) 2009 by Manuela Angelucci, Giacomo De Giorgi, Marcos A. Rangel, and Imran Rasul. All rights reserved. Short sections of text, not to exceed two paragraphs, may be quoted without explicit permission provided that full credit, including $\odot$ notice, is given to the source. 
Family Networks and School Enrolment: Evidence from a Randomized Social Experiment Manuela Angelucci, Giacomo DeGiorgi, Marcos A. Rangel, and Imran Rasul NBER Working Paper No. 14949

May 2009

JEL No. I21,J12,O12

\begin{abstract}
$\underline{\text { ABSTRACT }}$
We present evidence on whether and how a household's behavior is influenced by the presence and characteristics of its extended family. Using household panel data from the Progresa program in rural Mexico, we exploit information on the paternal and maternal surnames of heads and spouses in conjunction with the Spanish naming convention to identify the inter and intra generational family links of each household to others in the same village. We then exploit the randomized research design of the Progresa evaluation data to identify whether the treatment effects of Progresa transfers on secondary school enrolment vary according to the presence and characteristics of extended family. We find that Progresa only raises secondary enrolment among households that are embedded in a family network. Eligible but isolated households do not respond. The mechanism through which the extended family influences household schooling choices is the redistribution of resources within the family network from eligibles that receive de facto unconditional cash transfers from Progresa, towards eligibles on the margin of enrolling their children into secondary school.
\end{abstract}

\author{
Manuela Angelucci \\ Economics Department \\ University of Arizona \\ Tucson, AZ 85721 \\ angelucm@eller.arizona.edu \\ Giacomo DeGiorgi \\ Department of Economics \\ Stanford University \\ 579 Serra Mall \\ Stanford, CA 94305 \\ and NBER \\ degiorgi@stanford.edu
}

\author{
Marcos A. Rangel \\ University of Chicago \\ rangelm@uchicago.edu \\ Imran Rasul \\ University College London \\ Department Of Economics \\ Drayton House \\ 30 Gordon Street \\ London WC1E 6BT \\ United Kingdom \\ i.rasul@ucl.ac.uk
}




\section{Introduction}

Economists usually focus on the nuclear family as the unit of analysis from which to study household behavior. Indeed, standard models of household decision making, such as the unitary model [Becker 1981], bargaining models [Manser and Brown 1980, McElroy and Horney 1981], and collective choice models [Chiappori 1988] all emphasize the preferences and resources of household members in shaping outcomes. Moreover, it is typically not possible to empirically identify the precise familial ties between households in survey data.

However, every household is actually embedded within an extended family network. If extended families shape the objectives and constraints relevant for households within them, then neglecting the role of this network leads to an incomplete understanding of household behaviors. The extended family may be especially relevant for household behavior in economic environments characterized by missing markets, correlated shocks, informal institutions of contract enforcement, and large scale policy interventions that affect many households in the local economy.

All these features apply to the empirical context of this paper, which uses household panel data from the Progresa social assistance program in rural Mexico. Progresa provides cash transfers to households conditional on their childrens' school attendance. In this paper we first exploit information on the paternal and maternal surnames of heads and spouses in conjunction with the Spanish naming convention in Mexico to identify the inter and intra generational family links of each household to others in the village. We then exploit the randomized design of the Progresa evaluation data to identify whether the treatment effects of Progresa transfers on school enrolment vary according to the presence and characteristics of extended family members.

Two key intuitions underlie our analysis. First, Progresa exogenously shifts the resources available to individual households and to their family network as a whole. Second, families are able to enforce implicit contracts of resource sharing. Hence Progresa can induce differential responses between connected households - namely those embedded within family networks, and those that are socially isolated in the sense that none of their extended family live in close proximity and are not therefore subject to the change in resources that Progresa provides. $^{1}$

While undoubtedly other households outside the extended family network also influence behavior, there are good reasons to focus on family networks, rather than friendship networks say, as being the core group within which resources are shared. First, evolutionary biology suggests preferences are defined over the family dynasty, as is commonly modelled within an

\footnotetext{
${ }^{1}$ Our analysis relates to the literature on risk pooling arrangements across households. While such ex post risk pooling mechanisms have been documented in developing country settings, formal tests of the Pareto efficient allocation of risk being achieved at the village level are typically rejected [Townsend 1994, Ligon 1998, Dercon and Krishnan 2000]. There is stronger evidence of risk pooling within ethnic groups [Deaton 1992, Udry 1994], sub-castes [Munshi and Rosenzweig 2005], and family and friends [Rosenzweig 1988, Fafchamps and Lund 2003, La Ferrara 2003, Cox and Fafchamps 2007].
} 
overlapping generations framework. Moreover there are specific inter-generational investments such as those into children's education - that have no counterpart in friendship ties, and provide long run incentives for family members to reciprocate in resource sharing arrangements. Finally, the transactions costs of sharing resources with non-family members may be higher because it is both more costly to observe outcomes outside the family network, and fewer mechanisms exist by which to punish non-family members that renege on such arrangements [La Ferrara 2003]. ${ }^{2}$

We exploit three key data features. First, we combine information on the paternal and maternal surnames of household heads and their spouses, with the Spanish naming convention to build two types of extended family link within the same village - (i) inter-generational links, such as those from the head and spouse to their parents, and to their adult sons and daughters; (ii) intra-generational links, such as those from the head and spouse to their brothers and sisters. Combined with information from household rosters that identify extended family members that co-reside in the household, this provides an almost complete mapping of extended family structures across 506 villages, covering around 22,000 households and over 130,000 individuals. To the best of our knowledge, this is the first time such a large scale mapping has been conducted.

Second, we exploit the multiple components of Progresa, each of which provides cash transfers conditional on a different household behavior. One component provides cash transfers conditional on the attendance of children in primary and secondary school. However, as preprogram primary school enrolment rates are above $90 \%$, transfers provided for this purpose represent a de facto unconditional cash transfer for households with primary school aged children. In contrast pre-program secondary enrolment rates are $65 \%$ so that for many households cash transfers will be obtained only if a change in behavior is induced. This is important because the value of transfers only corresponds to between one half to two thirds of the full time child wage in the survey villages [Schultz 2004], and so do not fully compensate for foregone earnings of secondary school aged children employed full time in the labor market.

Hence if households are credit constrained, Progresa's effect on secondary enrolment may be a function of the presence of primary school aged children, who receive de facto unconditional transfers. In particular, households can use these transfers to supplement those specifically conditioned on secondary school enrolment, thus fully offsetting the opportunity costs of enrolling children into full time secondary school. This channel affects both connected and isolated households. In addition, if families share resources, and in particular they share the unconditional transfers obtained from the primary school component of Progresa, the response of connected households will also depend on the demographic composition of eligible households within their

\footnotetext{
${ }^{2}$ We therefore also contribute to the literature on the effects of extended family on household behavior, such as for consumption [Altonji et al 1992]; inter-generational transfers [Cox and Jakubson 1995, Altonji et al 1997, La Ferrara 2003, Behrman and Rosenzweig 2006]; childrens' education choices [Loury 2006]; and non-resident parental investments into children [Weiss and Willis 1985].
} 
family network. This drives a wedge between the program responses of connected and isolated households in terms of secondary enrolment.

Third, we exploit the randomized research design used to evaluate Progresa. Of the 506 sampled villages, 320 were randomly assigned to be a treatment group, namely villages where Progresa would be implemented, and 186 villages were controls. Data was collected on a panel of around 22,000 households every six months over the pre and post-program periods. In each village the baseline survey provides a complete census of all eligible and all non-eligible households. Under standard assumptions this research design identifies the average treatment effect of Progresa from a comparison of eligibles in treatment and control villages. The core of our analysis identifies whether this treatment effect varies across connected and isolated households.

Our main descriptive findings are as follows. First, $20 \%$ of couple headed households are isolated in the sense that none of their extended family reside within the village, while $80 \%$ are embedded within an extended family network. As a point of comparison, we note that $15 \%$ of households are single headed. Second, there are no significant pre-program differences between isolated and connected households in terms of their primary and secondary enrolment rates, and overall poverty levels. Third, among connected households, the extended family of the head is more likely to reside in the same village than the extended family of his spouse, and this relates to higher levels of female migration at the time of marriage. ${ }^{3}$

Our main empirical findings are as follows. First, despite baseline enrolment rates being similar in connected and isolated households, only connected households respond to the program in terms of secondary school enrolment. The average treatment effect of Progresa on them is significantly different from zero at around 9\%. In contrast, eligible but isolated households do not respond - their treatment effect varies between $-.2 \%$ and $.9 \%$ and is never significantly different from zero. ${ }^{4}$

Our second set of results provides direct evidence on the interplay between the design features of Progresa, whether a household is connected or isolated, and its response to the program. In particular, we find that the marginal response of connected households in terms of secondary enrolment depends on the demographic composition of their own household, and the demographic composition of eligible households within their extended family. The particular pattern of responses we document, that are a function of primary school aged children both in the household and the eligible portion of the extended family network as a whole, point to resources being redistributed within family networks towards households that are on the margin of enrolling children into secondary school. These are those households that themselves receive effectively unconditional Progresa transfers for the primary school enrolment of their children.

\footnotetext{
${ }^{3}$ This is similar to the findings of Rosenzweig and Stark [1989] who examine marital arrangements in rural India.

${ }^{4}$ We build on earlier findings on the effects of Progresa on enrolment [Schultz 2004, Attanasio et al 2005, Todd and Wolpin 2006]. This literature has not emphasized the influence of extended families on schooling choices.
} 
Finally, we complement our main results by considering which specific family members share resources and why. Among sibling links, the household's response to Progresa in terms of secondary school enrolment is sensitive to the eligibility status of their siblings, and in particular, whether eligible siblings obtain unconditional transfers from having primary school aged children. Among parent-adult child links, parental households are again sensitive to the eligibility status of their adult children and the presence of younger children in their households.

These results together, on the influence of specific family links, consistently point to resources being redistributed within the network from eligibles that receive largely unconditional transfers for the primary school enrolment of their children, towards eligibles that are on the margin of enrolling children into secondary school. The pattern of results also helps rule out other mechanisms behind why family networks matter in this setting, such as information sharing or providing access to communal land. This is because if families mattered through these other channels, we would not expect household responses to Progresa in terms of secondary school enrolment to depend on the extent to which other households in the family network were eligible, or the extent to which these eligible households received transfers specific to their primary school aged children.

Although our analysis exploits the particular design features of Progresa, the results have far wider implications. The descriptive analysis presents new evidence on the nature of extended family structures. This can serve as a foundation for future work on understanding behavior in the markets for marriage, and insurance, for example. The econometric evidence highlights how the design of welfare programs in developing countries cannot be done in isolation from an understanding of behavior within extended family networks.

The paper is organized as follows. Section 2 describes the Progresa program and data. Section 3 discusses how we construct family links and provides descriptive evidence on them. Section 4 presents the empirical method and supportive evidence on the underlying identifying assumptions. Section 5 presents our baseline results on whether and why being connected influences program responses. Section 6 presents evidence on how specific family links shape schooling decisions. Section 7 concludes with a discussion of the broader implications of our analysis. Additional results and robustness checks are in the Appendix.

\section{The Progresa Program and Evaluation Data}

\subsection{Transfers}

Progresa is an ongoing publicly funded social assistance program in Mexico. It is designed to alleviate poverty by fostering human capital accumulation through two channels - (i) the provision of cash transfers to households conditional on children's attendance in primary and secondary school grades; (ii) the provision of cash transfers and nutritional supplements conditional on attendance at local health facilities. This component of Progresa targets households 
with pregnant or lactating women, and with children aged less than five. ${ }^{5}$

Central to the analysis in this paper is that the extended family members of any given household can be eligible for transfers even if they have no secondary school age children. For example, households with primary aged children, very young children and those with no children but a pregnant women in them, can be eligible for the primary school, health, and nutritional components respectively. Hence if families share resources, the response to Progresa of households with secondary school age children will be partly determined by the demographic composition of all eligible family members, not just those that also have secondary school aged children.

Transfers for school enrolment are paid bimonthly and conditional on the child attending classes at least $85 \%$ of the previous 60 days. Transfers are larger for higher school grades, and for girls within any given grade. The average monthly transfer to eligible households is non-negligible, corresponding to $20 \%$ of the value of monthly consumption expenditures preprogram [Skoufias 2005]. ${ }^{6}$ However, the value of transfers only corresponds to between one half to two thirds of the full time child wage in the survey villages [Schultz 2004]. Hence the most credit constrained households should not be induced to change their schooling choices by such transfers alone.

Although both the education and health components are conditioned on household behavior, the extent to which households need to change behavior to obtain the transfers depends on their pre-program choices. As documented in Section 4, pre-program primary enrolment rates are above $90 \%$. Hence transfers provided to enrol children into primary school effectively represent a pure income effect on households. In contrast pre-program secondary enrolment rates are closer to $65 \%$. Hence given the value of transfers conditional on secondary enrolment do not compensate for the loss of income earned by children in the labor market, the likelihood the program increases secondary enrolment rates will depend partly on the demographic composition of children in the household. In addition, if families share resources, the response of connected households will in general depend on the demographic composition of eligible households within their entire family network. This channel drives a wedge between the behavioral responses of connected and isolated households to the program in terms of the secondary school enrolment.

Of course, some portion of the transfers received for secondary school enrolment may also be viewed as de facto unconditional cash transfers that can be redistributed within the family

\footnotetext{
${ }^{5}$ The program was initially offered to 140,544 households in 1997, expanding to more than 2.6 million recipient households throughout rural Mexico by the end of 1999. This constitutes around $40 \%$ of all rural families and one ninth of all families in Mexico. The total annual budget of the program in 1999 was equivalent to just under $20 \%$ of the federal poverty alleviation budget or .2\% of GDP [Skoufias 2005]. The program was expanded to urban areas in 2003 under the name of Oportunidades. We do not exploit this expansion into urban areas for our analysis.

${ }^{6}$ By November 1999 the bimonthly transfer ranged from 160 pesos for third grade, to 530 (610) pesos for boys (girls) in ninth grade. The total amount received bimonthly by a household cannot however exceed 1500 pesos.
} 
if a household has a fraction of its children of secondary school age enrolled when Progresa is initiated. However, as discussed in Section 6, because the majority of households tend to have either none or all of their children enrolled in secondary school, there are far fewer such households than those that receive de facto unconditional cash transfers related to their primary school aged children.

Finally, the health and nutrition components of the program require the periodic attendance of mothers at local health clinics. Households are likely to view this component as somewhere between the purely unconditional transfers obtained for primary schooling, and the conditional transfers obtained for secondary schooling. Again it will be the case that the response in terms of secondary school enrolment will in general be influenced by the presence of young children in the household to whom this component is targeted, and for connected households, the presence of young children in eligible households within the family network as a whole. ${ }^{7}$

\subsection{Eligibility and The Evaluation Data}

In 1997 households were classified as either being eligible (poor) or non-eligible (not poor) for Progresa transfers according to a household poverty index. This index is a weighted average of household income (excluding children), household size, durables, land and livestock, education, and other physical characteristics of the dwelling. The index is designed to give relatively greater weight to correlates of permanent income rather than current income.

Around half the households were classified as poor and therefore eligible for Progresa. Households were informed that their eligibility status would not change at least until November 1999, irrespective of any variation in household income. Moreover, the monetary value of transfers that eligibles were entitled to was determined by the age and gender composition of the children resident in the household at baseline. There are therefore no incentives for eligibles to foster children from non-eligibles with the aim of obtaining more transfers. Finally, a distinguishing feature of Progresa is that households were clearly informed about the program's introduction through village-wide assembly meetings. These meetings also ensured households agreed with their designated eligibility status. Hence take-up rates for at least one component of the program among eligibles are over $90 \%$ and we do not therefore distinguish between intent-to-treat and treatment effects. ${ }^{8}$

\footnotetext{
${ }^{7}$ The required frequency of attendance varies depending on age - children younger than 4 months are required to attend three check ups, those aged 4 to 24 months attend 8 check ups, those aged 2 to 4 attend every 4 months, those aged 5 to 16 attend every six months, pregnant women attend five check ups during their prenatal period, lactating women attend two check ups, and adults are required to attend annual check ups [Skoufias $2005]$.

${ }^{8}$ A group of households - referred to as densificados - had their eligibility status reclassified from non-eligible to eligible in October 1998. A non-random subset of them began receiving Progresa transfers in treatment villages prior to November 1999. As no precise algorithm exists to determine which densificados received transfers in treatment villages, no counterfactual set of households exists for them in control villages. As we can define extended family links to and from these households, all the reported descriptive statistics on extended families include links to and from densificados. We do not consider changes in enrolment among densificados in our analysis.
} 
To evaluate Progresa, an experimental research design was implemented and household data collected on a panel of around 22,000 households every six months in 506 villages between March 1998 and November $1999 .{ }^{9}$ Of the 506 villages, 320 were randomly assigned to the treatment group, namely locations where Progresa would be later implemented in May 1998, and 186 villages were assigned to be control villages. The first two waves were collected pre-program (October 1997, March 1998). Transfers were first distributed in May 1998, hence the remaining waves (October 1998, May 1999, November 1999) correspond to the post-program period. To understand whether household behavior is influenced by the characteristics of extended family members of both the head and spouse, we focus attention on the $85 \%$ of households that are couple headed throughout. ${ }^{10}$

\section{Constructing Extended Family Links}

\subsection{Surnames and the Matching Algorithm}

To identify both the intra-generational and the inter-generational family links between any two households in the same village we exploit information on surnames provided in the third wave of data, and in conjunction with the naming convention in Mexico. ${ }^{11}$

Mexicans use two surnames - the first is inherited from the father's paternal lineage and the second from the mother's paternal lineage. For example, former Mexican president Vicente Fox Quesada would be identified by his given name (Vicente), his father's paternal name (Fox) and his mother's paternal name (Quesada). In the evaluation data, respondents were asked to provide the - (i) given name; (ii) paternal surname; and, (iii) maternal surname, for each household member. Hence couple headed households have four associated surnames - the paternal and maternal surnames of the head, and the paternal and maternal surnames of his wife. $^{12}$

\footnotetext{
${ }^{9}$ Villages were selected on the basis of a marginality index constructed from information on the share of illiterate adults in the village; share of dwellings without water, drainage systems, electricity, and with floors of dirt; average number of occupants per room in village households; share of population working in the primary sector; distance from other villages, and health and school infrastructures in the village.

${ }^{10}$ Control villages began receiving Progresa transfers in December 1999. In 1997, eligible households in control villages were informed they would become part of the program at the end of 1999 conditional on them still being eligible and the program continuing.

${ }^{11}$ Two concerns arise from the surnames data being measured in the first wave of post-program data. First, households may endogenously respond to the program by changing household structures, in particular, by artificially forming new households in order to increase the number of eligibles in the family. This concern is ameliorated by the fact that the register of eligible households was drawn up at baseline, and only households recorded to be eligible at that point were later entitled to receive transfers. Moreover, although there is an increase in the number of households from the baseline to October 1998, this increase is proportionately the same in both treatment and control villages. A second concern is that the program may affect the migration of the household head or of his spouse. However, only .4\% (.5\%) of households in wave 3 (5) report having a migrant head or spouse. Moreover the share of households with such migrants does not differ across treatment and control villages.

${ }^{12}$ The precise wording of the question in Spanish is, "Dígame por favor el nombre completo con todo y apellidos de todas las personas que viven en este hogar, empezando por (jefe del hogar) - (i) nombre; (ii) apellido paterno;
} 
Figure 1 illustrates the matching algorithm. To define each family link, we use information on two of the four surnames. Consider household $\mathbf{A}$ at the root of the family tree. The head of the household has paternal and maternal surnames $F 1$ and $f 1$ respectively. His wife has paternal and maternal surnames $F 2$ and $f 2$ respectively. ${ }^{13}$

The children of the couple in household $\mathbf{A}$ will adopt the paternal surnames of their father $(F 1)$ and mother $(F 2)$. Hence we define there to be a parent-son relationship between households $\mathbf{A}$ and $\mathbf{B}$ if - (i) the paternal surname of the head in household $\mathbf{B}$ is the same as the paternal surname of the head in household $\mathbf{A}(F 1)$; and, (ii) the maternal surname of the head in household $\mathbf{B}$ is the same as the paternal surname of the spouse in household A (F2). Parent-daughter relationships can be similarly defined. Moreover, intra-generational family ties between siblings can also be identified. For example, the heads of households $\mathbf{B}$ and $\mathbf{C}$ are identified to be brothers if they share the same paternal and maternal surnames.

Figure 1 shows all households to be couple headed solely to ease the exposition. To deal with the $15 \%$ of households that are single headed we use information on the gender of the head to accurately define family links. Finally, we impose the following restrictions when defining family links - (i) inter-generational links exist when the relevant individuals have at least 15 years age difference, and no more than 60 years age difference between mother and child; (ii) intra-generational links exist when the individuals have at most 30 years age difference.

However, there are limits to which information on surnames can be used to construct family ties. Consider links from household $i$ to a single headed household $j$. As Figure 1 shows, the fact that household $j$ is single headed does not affect the construction of links from the head and spouse of household $i$ either to their children or to their siblings. However, links from the head (spouse) of household $i$ to the household of his (her) parents can only be identified if both his (her) parents are alive and resident together. This is because this particular family link is identified using information from household $j$ on the paternal surnames of both the head and spouse. $^{14}$

We define family links within villages because Progresa is implemented at the village level. Hence geographically proximate family members are those most relevant to understand household behavior if families share resources. Isolated households may well have extended family

(iii) apellido materno". We cleaned the surnames data as follows - (i) we removed non-alphabetical characters, replaced "Sin Apellido" (no surname) with missing values, and corrected some obvious typos based on intrahousehold surname checks; (ii) we imputed a small number of missing female surnames from wave 2; (iii) we verified surnames using the same information from wave 5 , and verified the relationship to the household head using wave 1 data. No information on surnames is available in the first wave of data. The head of household is originally defined to be the main income earner. In a very small number of cases the head of a couple headed household is reported to be a women. To keep clear the exposition, we redefine the head to be male in such cases.

${ }^{13}$ Paternal (maternal) surnames are indicated in upper (lower) case. First names are not shown as they are irrelevant for the matching algorithm. In Anglo Saxon countries, $F 1$ corresponds to the family name and $F 2$ corresponds to the spouse's maiden name.

${ }^{14}$ However this is unlikely to be a major issue. For example we note that female widows aged above 40 are $37 \%$ more likely to live as a dependent within a household, rather than head their own household, relative to a similar married woman. These single parents are then recorded in the household roster. 
elsewhere and share resources with them, but their family is unlikely to experience any resource changes due to Progresa because the data covers a period when the program was still being rolled out.

The Appendix provides more descriptive evidence on surnames in this setting, and discusses various forms of measurement error in the family links, some of which can be quantified. However, it is important to note that sources of measurement error that imply households are incorrectly labelled as connected when in fact they are isolated makes it less likely that any behavioral differences are found between households defined to be connected and isolated. In addition, the econometric analysis only exploits information on whether such family links exist for a household, not the number of such links. We also show the robustness of our main results to dropping households with potential measurement error in their surnames, and to limiting the sample to smaller villages where spurious links between households are less likely to be defined.

\subsection{The Number of Extended Family Links}

Table 1 shows the number of family links each household has to others in the village. The columns of the upper panel split family links into - (i) inter-generational links to parents and adult children who head their own households; (ii) intra-generational links to siblings who head their own households. We report each type of link from the head and spouse separately. The lower panel reports the number of corresponding family links that co-reside inside the household as measured from the household roster in wave 3. Using information on the relationship to the household head, we decompose these links into those from the head and spouse. Each type of link is reported separately for connected and isolated households. By definition, the upper panel reports that isolated households have no links to family members within the same village.

On links to extended family, Table 1 shows parents are many times more likely to reside outside rather than inside the household of their adult children. The number of parents present is higher for the head than for his spouse, and this is true for parents inside and outside the household. This is consistent with either the spouse migrating to the village, or women moving in with their husband's family within the same village. To shed more light on this we exploit data on spouse's marital history. Wives were asked about where they went to live after marriage $-49.3 \%$ stated that they went to live with their in-laws after marriage, and only $6.5 \%$ report living with their own parents. The key difference between spouses with and without parents resident in the village is that $85 \%$ of spouses that have their parents present in the village report remaining in the same village at the time of marriage. The figure for spouses that have no parental links in the village is only 61\%. Along other margins, women in connected households with and without parents in the village are similar. For example, they do not differ significantly in their ages at marriage, nor in the proportions that report their in-laws originally proposing the marriage $(56 \%)$.

The number of links to adult children are, by construction, identical for head and spouse. 
Given respondents' ages, there are many more young children inside than adult children outside the household. Sibling links are more likely to be outside the household, which is as expected given respondents' ages. Heads have more siblings links than their spouses, and this is again true for links both inside and outside the household. Overall, the upper panel shows that the average household has family ties to just over five other households in the same village, and that the majority of these family links are those of male heads of household. ${ }^{15}$

A concern is that isolated households may simply be those in which all family members reside under the same roof. The lower panel of Table 1 shows this is not true - the average household has around seven members and this is not different between connected and isolated households. Another explanation for why isolated households exist relates to geographic mobility. On this issue we note that while isolated and connected households are equally likely to report being resident in the same state of birth, unfortunately, the data does not contain information on how long individuals have been resident in the same village. However, we note that among isolated households, only $52 \%$ of spouses report living in same village as at the time of marriage, which is lower than that for spouses in connected households as reported above. ${ }^{16}$

Finally, we note that connected and isolated households are as likely to report receiving remittances from family members that have permanently migrated away in the five years prior to baseline. Hence isolated households do have family located somewhere, and may share resources with them. ${ }^{17}$ The key difference for our analysis is that their families are far less likely to receive Progresa resources since they live in different villages, and the program is being scaled up during the period of study. This drives a wedge between the program response of isolated and connected households, even if all families share resources.

To provide external validity to the links, the Appendix presents similar information from the Mexican Family Life Survey, that was collected in rural areas over a comparable time period.

\subsection{Family Networks}

Table 2 shows how the probability of having an extended family link of type- $j$ varies by eligibility across treatment and control villages. We first note that $20 \%$ of couple headed households are isolated. The incidence of not having extended family members geographically proximate in the same village is therefore at least as high as the incidence of single headedness, which affects

\footnotetext{
${ }^{15}$ In October 1998 the average age of heads (spouses) among couple headed households is 45.0 (40.5). The total number of siblings of the head is on average 2.23, implying his parents have 3.23 children that reside within the same village. In contrast, heads have on average 4.70 of their own children somewhere in the village. Again this is as expected given that siblings are older than adult children and so will be more likely to have migrated.

${ }^{16}$ Munshi and Rosenzweig [2005] provide evidence from India that those who migrate away from their subcaste lose the services of that network, including mutual insurance arrangements. The model they develop and test implies the wealthiest households are those with incentives to withdraw from such arrangements. However, in general, the relationship between wealth and exit is theoretically ambiguous [Banerjee and Newman 1998].

${ }^{17}$ There is however no information on pre-program transfers from other family members outside the village, including temporary migrants or family members in the place of birth if the household has itself migrated. Hence it is not possible to make inferences about whether the transactions costs of across village transfers are higher than within village transfers, due to asymmetric information say.
} 
$15 \%$ of households. We also see that links from the head are significantly more likely to exist than links from his spouse, and that intra-generational links are significantly more common than inter-generational links. These patterns hold for eligibles and non-eligibles in treatment and control villages. Reassuringly, in nearly all cases there are no significant differences in the extended family links of eligibles and non-eligibles between treatment and control villages, which as explained in Section 4, relates to an underlying identifying assumption for the empirical analysis. $^{18}$

Table 3 provides descriptive evidence on family network characteristics as a whole, by treatment and control villages. There are 1379 (817) family networks in treatment (control) villages covering 10559 (6471) households. In treatment villages, the first column shows that on average there are around 7.6 households in each family. The average village has around seven family dynasties so each dynasty encompasses $16 \%$ of all village households. The third column provides information on the diameter of the network - the largest distance between any two households in the network. This is around 2.4, implying family networks are unlikely to span more than three generations.

The remaining columns document how family networks vary. We consider characteristics that relate specifically to design features of Progresa that we exploit empirically. Networks span eligibility status - there are an almost equal number of eligibles and non-eligibles in the average family. Hence there is considerable scope for Progresa transfers to be redistributed within the family. Family networks also vary in the share of households within them that have primary and secondary school aged children. Hence, as shown in the final column, the potential value of transfers each household is eligible for and hence the amount of resources to be redistributed within the family, varies considerably between networks. Finally, Table 3 also decomposes the variation in each statistic into that arising between family networks across different villages, and across family networks within the same village. There is typically more variation within networks in the same village than across villages. This is important given that identification arises from across village comparisons of households with a given set of family characteristics.

\section{Empirical Method}

\subsection{Descriptive Evidence}

The empirical analysis estimates the response of eligibles to Progresa in terms of secondary enrolment rates, and explores whether these responses vary depending on the presence and characteristics of extended family members. To begin with, we denote the secondary enrolment rate of household $h$ in village $v$ in survey wave $t$ as $Y_{h v t}$. This is defined as the fraction of children aged between 11 and 16 resident in the household that are enrolled in school on survey

\footnotetext{
${ }^{18}$ The one exception is the proportion of non-eligibles with links from the spouse to her brother being significantly higher in controls. Our later analysis however focuses on the influence of same gender siblings.
} 
day in wave $t$. The behavioral response we focus on is the change in secondary enrolment within the same household over time, between November 1999 (wave 5) and October 1997 (wave 1), denoted $\Delta Y_{h v t}$. This corresponds to more than one academic year after Progresa is implemented. ${ }^{19}$

The left hand panel in Table 4 provides descriptive evidence on the pre-program levels of secondary school enrolment rates, and how they vary over time in treatment and control villages by eligibility status. While enrolment rates among eligibles at baseline are similar across treatment and control villages, by November 1999 eligibles in treatment villages have $6.9 \%$ higher enrolment rates than eligibles in control villages. This DD is positive and significant for both boys and girls enrolment, and consistent with previous studies, the proportionate increase is greater for girls. ${ }^{20}$

The central panel of Table 4 splits the sample between connected and isolated households. This reveals that eligible isolated and connected households have similar baseline levels of enrolment, implying that determinants of the levels of enrolment - such as credit constraints, information on the costs and benefits of schooling, or demand for child labor in the home do not, on average, explain baseline differences in the schooling choices between isolated and connected households. Hence isolated households are at least as well off - in terms of secondary enrolment - as connected households, and should not therefore be viewed as more vulnerable. This idea is reinforced by the fact that isolated and connected households do not differ in their poverty index at baseline, a measure of permanent income, as shown in Figure A2.

Despite similarities at baseline, there are significant differences in the program response of isolated and connected households. The DD in enrolment rates among eligible and connected households is $8.3 \%$ and significantly different from zero, while the DD for isolated households is close to zero. In short, the previously documented positive effects of Progresa on secondary enrolment are a combination of a large and significant effect on the $80 \%$ of connected households, and a close to zero effect on the $20 \%$ of isolated households. In line with this, we note that take-up rates for school related transfers - either secondary or primary - are consistently higher among connected households. Immediately after the initiating of Progresa, connected households have take-up rates that are $.8 \%$ higher, and this difference rises to $4.0 \%$ by November 1999. ${ }^{21}$

The last panel in Table 4 shows the baseline levels and changes over time in primary en-

\footnotetext{
${ }^{19}$ The enrolment rate is constructed from individual child observations that have complete information on the child's age, gender, and residence. Waves 1 and 5 are collected during the school year which runs from September to July. This eases concerns that households mis-report enrolment status either because children are on school vacation or have dropped out part way through the academic year. We later also use primary enrolment rates for some of the analysis - these are analogously defined for 6 to 10 year olds.

${ }^{20}$ Recall that the program design is such that households have no incentives to foster children in order to obtain greater transfers. Indeed, we note these changes in enrolment are driven by changes in the number of children enrolled in school, and not by the number of children resident in the household.

${ }^{21}$ Among non-eligibles, neither connected nor isolated households in treated villages have any significant changes in enrolment vis-à-vis analogous households in control villages (not shown).
} 
rolment rates for connected and isolated households. The baseline levels of primary enrolment are very high to begin with, and neither types of eligible household increase their enrolment rates relative to analogous households in control villages. This confirms that transfers from this component of Progresa are obtained without inducing any changes in behavior, and therefore essentially act as a pure income effect that can potentially be redistributed within the family network.

\subsection{Estimation}

We define three dummy variables - (i) $D_{h}=1$ if household $h$ is eligible, and zero otherwise; (ii) $P_{v t}=1$ if Progresa is in place in village $v$ in wave $t$, and zero otherwise, so $P_{v t}=0\left(P_{v t}=1\right)$ in the pre (post) program waves in treatment villages, and $P_{v t}=0$ in control villages for all $t$; (iii) $L_{j h}=1$ if household $h$ has family link- $j$ in the village, and zero otherwise. The existence of family links is treated as being time invariant. Although in the long run we expect family networks to endogenously adjust to the permanent presence of Progresa, our analysis treats networks as fixed over the time period considered. ${ }^{22}$ Our baseline specification is the following first differenced OLS regression where all differences correspond to those between November 1999 and October 1997,

$$
\Delta Y_{h v t}=\alpha+\beta_{1} \Delta P_{v t}+\beta_{2}\left(\Delta P_{v t} \times L_{j h}\right)+\beta_{3} L_{j h}+\boldsymbol{\lambda}^{\prime} \mathbf{X}_{h v}+\Delta u_{h v t}
$$

$\Delta Y_{h v t}$ is the change in secondary enrolment within the same household over time, and $\Delta u_{h v t}$ captures unobserved time varying household characteristics, and standard errors are clustered by village. Time invariant household determinants of enrolment - such as household preferences or ability - are differenced out in this specification. To capture any omitted time varying factors that would differentially drive enrolment rates in treatment and control villages and be correlated to family links $L_{j h}$, in (4.1) we control for a series of characteristics $\mathbf{X}_{h v}$ of the head, spouse, household, and village. Moreover we allow there to be a direct impact of the family link- $j$ on secondary enrolment to allow for the effect of having family present in the village to change over time, say because of changes in other public assistance programs. ${ }^{23}$

To see how this specification relates to our parameters of interest, consider the simplest

\footnotetext{
${ }^{22}$ In support of this, we reiterate that the share of households reporting a migrant head or spouse is only $.4 \%$ $(.5 \%)$ in wave $3(5)$, and that the share of households with such migrants does not differ across treatment and control villages. In the Appendix we show our main results to be robust to redefining family networks on the basis of additional information collected in May 1999.

${ }^{23}$ The controls in $\mathbf{X}_{h v}$ are the head and spouse's ages, literacy status, whether (s)he speaks an indigenous language, the household poverty index, whether the household owns any land, and household size at baseline. At the village level we control for the number of households in the village to capture any scale effects, the share of households that are eligible to capture any aggregate income effects, the marginality index for the village, and the village level enrolment rate at baseline among eligible and non-eligibles. This may correlate to distances to school facilities for example. Hence we do not exploit data from villages that have all eligible or all non-eligible households so the TTEs and ITEs are identified from the same set of villages. As randomization into treatment and control groups takes place within region, we control for regional fixed effects throughout.
} 
case in which $L_{j h}=1$ if the household has any extended family present and $L_{j h}=0$ if the household is isolated in that no members of its extended family live in the same village. If (4.1) is then estimated only for eligibles $\left(D_{h}=1\right), \beta_{1}+\beta_{2}$ identifies the average treatment effect of Progresa on eligibles in treated villages that are embedded within family networks $\left(L_{j h}=1\right)$. We denote this parameter as $T T E^{1}$. This difference-in-difference (DD) in secondary enrolment is estimated from a comparison of the average change in enrolment among eligibles in treatment villages with extended family present, relative to eligibles in control villages who also have family present.

Similarly, $\beta_{1}$ identifies the average response to the program among eligible but isolated households $\left(L_{j h}=0\right)$, denoted $T T E^{0}$, from the DD in enrolment of isolated households in treatment and control villages. If families share resources, there exists a wedge between the behavioral responses of connected and isolated households to Progresa, so that $T T E^{1}>T T E^{0}$.

If (4.1) is estimated only for non-eligibles $\left(D_{h}=0\right), \beta_{1}+\beta_{2}$ identifies the average indirect treatment effect of Progresa on non-eligibles in treatment villages that are embedded within extended family networks. We denote this parameter as $I T E^{1}$. Finally, when (4.1) is estimated for non-eligibles, $\beta_{1}$ identifies the average indirect treatment effect of the program among noneligible and isolated households, ITE $E^{0}$. These ITEs shed light on whether there exist within village spillovers of Progresa on secondary school enrolment. Spillovers onto non-eligibles may arise either because extended family networks span eligibles and non-eligibles and resource transfers take place between all households in the network, or because of general equilibrium effects of Progresa.

\subsection{Identification}

Equation (4.1) makes precise the assumptions required for the TTE and ITE parameters to be identified. First we require the standard twin assumptions of no cross village spillovers and random assignment of villages into treatment and control villages $\left(\operatorname{Cov}\left(\Delta P_{v t}, \Delta u_{h}\right)=0\right)$. In support of the first identifying assumption, we note that villages were, in part, included in the evaluation data because they were geographically remote. In terms of the second identifying assumption, it is has been previously documented that village characteristics do not significantly differ in treatment and control villages suggesting randomization worked [Schultz 2004, Behrman et al 2005]. Moreover, the descriptive evidence in Table 2 suggests the eligibles and non-eligibles are similar in terms of the existence of family links across treatment and control villages.

Together these assumptions imply the change in enrolment for eligibles and non-eligibles in the absence of treatment in treatment villages would have been, on average, identical to the change in enrolment in the absence of the program in control villages. In other words, eligibles (non-eligibles) in control villages provide a valid counterfactual for eligibles (non-eligibles) in treatment villages. 
To then estimate whether the TTEs and ITEs vary with regards to extended family links of type- $j$, namely to consistently estimate $\beta_{2}$, requires an additional assumption that the presence of link type- $j$ is uncorrelated with unobservables that drive the response to Progresa $\left(\operatorname{Cov}\left(L_{j h}, \Delta u_{h}\right)=0\right)$. However a central concern is that $\beta_{2}$ captures two effects $-(\mathrm{i})$ the response to the Progresa program differs according to whether a household is isolated or embedded within a family network; (ii) connected and isolated households differ in characteristics that drive responses to Progresa and are correlated to the presence of the extended family.

To isolate the impact of the extended family per se, we need to purge the estimates of factors that both drive the presence of extended family and responses to Progresa. To do this we proceed as follows. First, we estimate what are the correlates of extended family link of type- $j$ being present in the village or not, as detailed in the Appendix. These results, reported in Table A3, highlight that the following life cycle and cohort characteristics are robust predictors of whether extended family members reside in the same village or not - whether the head's (spouse's) age is above or below the median among couple headed households, whether the head (spouse) is literate, whether the household owns land, and whether household size at baseline is above or below the median among couple headed households. Using this analysis to guide our approach we then allow for a household's response to Progresa to be heterogeneous along each of these dimensions. Hence we estimate the following specification for eligibles and non-eligibles,

$\Delta Y_{h v t}=\alpha+\beta_{1} \Delta P_{v t}+\beta_{2}\left(\Delta P_{v t} \times L_{j h}\right)+\beta_{3} L_{j h}+\boldsymbol{\lambda}^{\prime} \mathbf{X}_{h v}+\sum_{i} \gamma_{2 i} Z_{i}+\sum_{i} \gamma_{3 i}\left(\Delta P_{v t} \times Z_{i}\right)+\Delta u_{h v t}$,

where $Z_{i}$ refers to each life cycle and cohort related dimension along which we allow the response to Progresa to be heterogenous, in addition to allowing for heterogeneous responses with the presence of the extended family link type- $j$. We additionally allow $Z_{i}$ to include the average village level enrolment rates among eligible and non-eligibles at baseline, to pick up any differential trends in enrolment by eligibility status. ${ }^{24}$ Overall, we therefore shed light on whether there exists a differential effect of being embedded within a family network or not, over and above any heterogeneous effects of characteristics that predict the existence of family links.

Finally, in support of the identifying assumption that $\operatorname{Cov}\left(L_{j h}, \Delta u_{h}\right)=0$, we provide three pieces of additional evidence. First, we estimated a propensity score for being connected, for each household based on the variables in $\mathbf{X}_{h v}$, regional fixed effects, and a full set of household demographic characteristics. The distribution of the propensity score by extended family links, reveals connected and isolated households to be, overall, balanced in household observables (Figure A1). Second, connected and isolated households have similar baseline enrolment rates, and similar levels and distributions of permanent income, as measured by the household poverty

\footnotetext{
${ }^{24}$ As the effects of Progresa are allowed to be heterogeneous along other dimensions $Z_{i}$, the TTEs and ITEs are evaluated at the mean value of each variable in $Z_{i}$.
} 
index (Figure A2). Third, the distribution of potential transfers available to isolated and connected households is very similar, again because the demographic characteristics of children do not differ across these household types at baseline (Figure 2A).

Any remaining econometric concerns relate to time varying unobservables, $\Delta u_{h}$, that - (i) are correlated to the existence of extended family; (ii) cause heterogeneous responses to Progresa; and, (iii) do not drive the baseline levels of enrolment to be different across connected and isolated households. In the Appendix we present a series of robustness checks that allow program responses to vary with more village level characteristics, we explore the robustness of the results in alternative subsamples of villages, and address concerns over unobserved household level characteristics such as economic shocks driving enrolment changes. ${ }^{25}$

\section{$5 \quad$ Does The Presence of Extended Family Matter?}

\subsection{Baseline Results}

To begin with, Column 1 of Table 5 benchmarks our estimates against the existing literature by reporting standard TTE and ITE estimates of Progresa from specification (4.1), by pooling eligibles and non-eligibles and interacting $\Delta P_{v t}, L_{j h}$, and $\left(\Delta P_{v t} \times L_{j h}\right)$ with the dummy for eligibility status, $D_{h}$. These are averaged across households irrespective of their extended family structure. The TTE estimate implies eligibles have a $7.8 \%$ increase in their secondary enrolment rate compared to eligibles in control villages, which is similar in magnitude to the previously documented program effects [Schultz 2004]. The ITE estimate implies non-eligibles in treatment and control villages have similar changes in their secondary enrolment. This suggests that, on average, there are no significant spillover effects of Progresa on the secondary enrolment of non-eligibles.

Column 2a estimates all four parameters of interest from a single regression. The result confirms that the TTE of Progresa is actually comprised of a large and significant effect on eligibles that have extended family members present in the village $\left(T T E^{1}>0\right)$, and a negligible and non significant effect among isolated households $\left(T T E^{0}=0\right)$.

There is no evidence of any ITEs on average for either households in family networks or isolated households. The fact that the $I T E^{1}$ is close is to zero itself implies there are no within family spillovers in secondary enrolment rates for these households. If recipient households redistribute some fraction of their transfers to non-eligibles within the same family network, then either - (i) the amount transferred is too small for the average $I T E^{1}$ to be positive and significant; or, (ii) recipient households do not themselves use such resources to increase

\footnotetext{
${ }^{25} \mathrm{~A}$ concern over the interpretation of the results stems from Progresa having a direct effect on fertility. If so the opportunity cost of female time will change and this may in turn drive schooling responses. Todd and Wolpin [2006] develop and test a dynamic structural model of schooling and fertility choices, and find that fertility rates are insensitive to the value of Progresa transfers, a result confirmed using a reduced form approach [Schultz 2004].
} 
secondary enrolment, but rather use them to change behavior along other margins such as consumption, say. ${ }^{26}$

At the foot of the table we report the triple differences, $\triangle T T E=T T E^{1}-T T E^{0}$, and $\triangle I T E=I T E^{1}-I T E^{0}$. The former captures the differential effect of Progresa between eligible connected and isolated households within treatment villages, and similarly, the latter captures the differential effect of Progresa between non-eligible connected and isolated households within treatment villages. Column 2a shows that connected eligibles experience a $8.4 \%$ increase in their secondary enrolment rate relative to eligible but isolated households within treatment villages. Moreover, the $\triangle I T E$ estimate implies non-eligibles with and without extended family present have almost identical changes in enrolment from the baseline period. Given these results on the ITEs, we now focus on the TTEs and return to discuss the ITEs in Section $7 .^{27}$

Column $2 \mathrm{~b}$ estimates (4.2) and allows responses to Progresa to vary along a number of additional dimensions that are correlated with the presence of extended family (Table A3), and also allows the response to Progresa to vary with the baseline village enrolment rates among eligibles and non-eligibles. We find the previous pattern of coefficients is robust to the inclusion of these interactions. Connected eligibles have a - (i) $9.2 \%$ increase in their enrolment rate relative to connected eligibles in control villages; (ii) $8.6 \%$ increase in their enrolment rate relative to isolated eligibles in treatment villages. The previous estimates do not appear to merely pick up heterogenous responses along observable dimensions that are correlated with the existence of extended family links. ${ }^{28}$

While we can never rule out with certainty that there exists some unobserved characteristic that drives the results, the stability of the estimates across specifications (4.1) and (4.2) is reassuring, and the requirements for such a variable to explain the data are stringent. In particular the unobserved characteristic should - (i) be correlated to the presence of extended family in the village; (ii) drive responses to Progresa; (iii) not drive the baseline levels of enrolment to be different across connected and isolated households.

Estimating (4.2) allows us to benchmark the magnitude of the effect of being embedded in

\footnotetext{
${ }^{26}$ Two further points are of note. First, the estimated parameters of interest are very similar whether they are estimated from separate regressions for connected and isolated households, or from a pooled regression. This implies the marginal effects of the other controls do not differ between connected and isolated households. Second, the coefficient on $L_{j h}, \beta_{3}$, which recall is not used to estimate any of our parameters of interest, is not significantly different from zero. This suggests the effect of having an extended family on the level of enrolment in the absence of Progresa, is not changing over this time period.

${ }^{27}$ As $\triangle I T E$ corresponds to coefficient on the interaction term, $L_{j h} . D_{h}$, the results suggest there is no differential effect of having extended family by eligibility status. Reassuringly, this is in line with the presence of extended family not proxying for some unobservable that varies with eligibility status and drives enrolment over time.

${ }^{28}$ Two simple explanations of this result would be that - (i) isolated households have higher enrolment rates to begin with and so have less scope to respond to the program; (ii) trends in enrolment rates among isolated households are different to others households over this time period. Neither of these explanations is supported by the data. Although isolated households do have slightly higher enrolment rates than households embedded in family networks at baseline, these enrolment rates are overtaken by November 1999 by the other households. Second, the pattern of coefficients on the ITEs rule out the explanation that isolated households are naturally changing their enrolment rates over this time period.
} 
a family network vis-à-vis other observable characteristics. We find that - (i) the magnitude of $T T E^{1}$ is larger than the TTE of most other observable characteristics; (ii) there are few observable dimensions along which household behavior is as heterogenous as with regards to whether members of the extended family are present or not. For example, the TTE of the household owning land is .082, the TTE of the household not owning land is .065. While both these TTEs are significant at the $1 \%$ level, the difference between them is not significantly different from zero. ${ }^{29}$

We next repeat the analysis for boy's and girl's secondary enrolment separately. Columns 3a and $3 \mathrm{~b}$ estimate (4.2) and show that, first, connected eligibles significantly increase the enrolment of boys and girls more than analogous households in control villages. Second, eligible but isolated households do not respond to the program in terms of boys enrolment, although the $T T E^{0}$ estimate is imprecisely estimated. As a result, the $\triangle T T E$ shows that the null hypothesis that within treated villages connected and isolated households have the same response cannot be rejected. Third, eligible but isolated households do not respond to the program in terms of girls enrolment, despite the monetary value of conditional cash transfers being higher for girls' enrolment, and the baseline level of girls's enrolment being lower.

Having established the importance of being embedded within a family network for a households response to Progresa, we now begin to unpack why this is the case. To begin with, a necessary condition behind why connected and isolated households respond differentially to the program, is that the level of transfers conditional on secondary enrolment is not sufficient to compensate the average eligible household for the opportunity costs of child labor. To provide some evidence on this we use cross sectional variation in adult wage rates in October 1998 to identify villages with above and below the median level of adult wages.

The results show that in villages where wages are sufficiently high - (i) in terms of boys secondary enrolment, neither connected nor isolated households respond to Progresa (Column 4a); (ii) in terms of girls secondary enrolment, it remains the case that only connected households respond to the program (Column 4b). If children are substitutes for adults in the local labor market so that their wages are positively correlated with adult wages, and if boys are more likely to be engaged in labor market activities relative to girls, then the results suggest the magnitude of transfers is not large enough to induce many households to change their behavior and increase the school enrolment of boys. Moreover, for connected households, there exist limits to the resources family networks can redistribute towards members with secondary school aged children. ${ }^{30}$

\footnotetext{
${ }^{29}$ The TTEs of the head being above (below) the median age among all couple headed households is .090 (.062), the spouse being above (below) the median age is .070 (.082), the head being literate (illiterate) is .061 (.118), the spouse being literate (illiterate) is .061 (.099), and the household size at baseline being above (below) the median of all couple headed households is .041 (.096). These TTEs are all significant at the $1 \%$ level. The difference in TTEs are not significantly different from zero except along two margins - the head being literate or not $(\triangle T T E=.057$ and is significant at the $10 \%$ level), and household size at baseline being above or below the median $(\triangle T T E=-.054$ and is significant at the $5 \%$ level).

${ }^{30}$ Using wages as measured in October 1998 may be problematic if in villages where children withdraw from the
} 
A second important factor underlying why connected and isolated households may respond differentially to the program is that extended families share resources. We therefore check whether family wealth is correlated to secondary enrolment rates at baseline for connected households. To do so, we regress the baseline enrollment rate against the set of controls described above, and additionally control for the average poverty index - which is positively related to family wealth - among households in the extended family. The result in Column 5 shows that wealthier households have significantly higher enrolment rates at baseline. The coefficient implies that if there were to be a one standard deviation increase in the poverty index of the average family member, the households secondary enrolment rate would rise by $2 \%$, relative to a baseline enrolment of $65 \%$.

In the Appendix we present a series of robustness checks on our main result that only connected households respond to Progresa. The first series of checks relate to concerns over the surnames information and matching algorithm. In particular we show the robustness of the baseline results to - (i) potential measurement error in surnames; (ii) limiting the sample to smaller villages where there is less likelihood of spurious family links being defined; (iii) the fact that our matching algorithm may measure the intrinsic value of surnames rather than having anything inherently to do with extended family links. The second series of checks address - (i) the concern that there are unobserved village level characteristics that drive both the presence of isolated households and their differential response to Progresa; (ii) the concern that there may be unobserved time varying household characteristics that drive their program responses such as whether they are subject to economic shocks post-program; (iii) the underlying identifying assumption that there are no spillover effects from treatment to control villages; (iv) the underlying assumption that extended family networks are not changing over time. $^{31}$

\subsection{Understanding Why Families Matter}

To understand why connected and isolated households respond differently, we exploit the design feature of Progresa that transfers provided conditional on primary enrolment effectively act as a pure income effect on households. This implies, first, households with and without primary school aged children should respond differentially to Progresa in terms of secondary enrolment. Second, if families share resources, then the differential response between connected and isolated

labor market as a result of the program, are those that experience the greatest adult wage increases. However, October 1998 corresponds to only five months after the introduction of the program. Hence wages are unlikely to have adjusted to such an extent so as to change the cross sectional ranking of villages by adult wages. Moreover we note that the correlation over time in adult wages in the 212 villages in which wages are available both at baseline and in October 1998, is .749.

${ }^{31} \mathrm{An}$ additional concern is that if children can flexibly supply any amount of hours to the labor market, then children may enrol in school $85 \%$ of their time - just sufficient to obtain Progresa transfers - and then devote the remaining $15 \%$ of their time to continue earning in the labor market. This hypothesis is not supported by the data. Attendance rates in November 1999 are over $95 \%$ for both boys and girls, suggesting indivisibilities or fixed costs in supplying labor to the market. 
households depends on the presence of primary school aged children in eligible households within the extended family.

On the first mechanism, we estimate how the average treatment effect varies with the value of transfers received by the household, and the presence of primary school aged children in the household. On the second mechanism, we estimate how the average treatment effect varies with the average value of transfers received by eligibles in the extended family of connected households, and the presence of primary school aged children in the family network. As transfers are provided conditional on household behavior, the actual transfers received are endogenously determined. We therefore proxy actual transfer receipts with the potential value of transfers the household could have received, as measured in October 1998. This is determined by the demographic characteristics of children in the household at baseline.

Figure 2A shows that the distribution of potential transfers available to isolated and connected households is very similar, because the demographic characteristics of children in isolated and connected households do not differ at baseline. Figure 2B plots the potential transfers each eligible connected household with secondary school age children receives against the average potential transfer eligible households in its family network are entitled to. The correlation between them is only -.01, because, as documented in Table 3, there exists considerable variation in the demographic characteristics of children across households within the same family network.

We then use the following specification to estimate how, for eligibles, the response to Progresa varies with the potential transfers received by household $h$ itself $\left(T_{h}^{O}\right)$, and with the average value of transfers received by eligibles among the extended family $\left(T_{h}^{F}\right)$,

$$
\Delta Y_{h v t}=\begin{aligned}
& \alpha+\beta_{1}^{O}\left(\Delta P_{v t} \times T_{h}^{O}\right)+\beta_{1}^{F}\left(\Delta P_{v t} \times T_{h}^{F}\right)+\beta_{2}^{O} T_{h}^{O}+\beta_{2}^{F} T_{h}^{F} \\
& +\boldsymbol{\lambda}^{\prime} \mathbf{X}_{h v}+\sum_{i} \gamma_{2 i} Z_{i}+\sum_{i} \gamma_{3 i}\left(\Delta P_{v t} \times Z_{i}\right)+\Delta u_{h v t}
\end{aligned}
$$

where all other controls are as previously defined, and standard errors are clustered by village. The parameter of interest is how the response to Progresa varies with the intensity of treatment,

$$
E\left[\Delta Y_{h v t} \mid \Delta P_{v t}=1, T_{h}^{O}, T_{h}^{F}, \mathbf{X}_{h v}, Z_{i}\right]-E\left[\Delta Y_{h v t} \mid \Delta P_{v t}=0, T_{h}^{O}, T_{h}^{F}, \mathbf{X}_{h v}, Z_{i}\right]=\beta_{1}^{O} T_{h}^{O}+\beta_{1}^{F} T_{h}^{F}+\sum_{i} \gamma_{3 i} Z_{i}
$$

As potential transfers are defined for eligibles in both treatment and control villages, this is identified from a comparison of eligibles in treatment villages with a given value of potential transfers, relative to eligibles in control villages that have an identical value of potential transfers. Both sets of households also have the same family characteristics (connected or isolated). By controlling directly for the level of potential transfers the household and average family member are eligible for in (5.1), we capture any direct effects the demographic composition of 
the household and its extended family have on changes in secondary enrolment. ${ }^{32}$

Table 6 presents the results. The upper (lower) panel shows the results for households with (without) primary school aged children in them at baseline. This allows us to assess any interplay between the own and family transfers and whether the household is on the margin of enrolling children into secondary school because it receives unconditional transfers for primary school aged children. Throughout we evaluate (5.2) at the mean values of $T_{h}^{O}, T_{h}^{F}$, and each $Z_{i}$.

Column 1 estimates the program response among isolated households. We see that the TTE is not significantly different from zero for isolated households, irrespective of whether they have any primary school aged children in them or not. Repeating the exercise for connected households in Column 2 shows that, on average, there is a positive and significant TTE for households both with and without primary school aged children.

The remaining Columns shed light on how these TTEs vary with the demographic composition of the eligible family network. We first note that baseline enrolment rates are not significantly different between connected households embedded in family networks in which the minority of their extended family is both eligible and have primary school aged children, and those embedded in families where the majority of members are both eligible and have primary school aged children. This is the case both for those connected households without primary school aged children themselves, and those with primary school aged children. Hence it is meaningful to compare the behavioral response of response to Progresa as the characteristics of their extended family change across the remaining columns of Table 6 .

Column 3 focuses on families in which the minority of members are both eligible and have primary school aged children. In such networks, Progresa leads to a relatively small increase in available resources per household. The upper panel shows that households with primary school aged children in such families significantly respond to the program. In contrast, the lower panel shows that connected households that receive no unconditional transfers themselves are not significantly influenced by the flow of resources into their household, or into the households of eligible family members.

Hence there exists a subset of connected households who do not respond to Progresa namely those that receive no unconditional transfers themselves, and are part of family networks that potentially receive only a small cash injection from Progresa. This is consistent with resource sharing within family networks if some part of the change in resources are redistributed towards those with primary school children who are on the margin of being able to enrol their children into secondary school.

A useful thought experiment is to ask what would have been a household's response to the program if it were the only household in its family network to obtain transfers? To answer this, Column 3 reports (5.2) evaluated at $T_{h}^{F}=0$. The estimate implies if a household is the

\footnotetext{
${ }^{32}$ For example, families with a larger share of primary school aged children may be learning more quickly about the net benefits of secondary education for their older children, other things equal.
} 
only member of its extended family to obtain transfers, it does not significantly respond to the program in terms of secondary school enrolment. As shown in the upper panel, this is true even for those households who have primary school aged children and are closer to being able to fully offset the opportunity costs of secondary school enrolment. This pattern of behavior that connected households do not respond to the program if others in their network are noneligible - is also found throughout the next Section, where we consider how program responses vary with the presence and eligibility status of particular extended family members.

Finally, Column 4 focuses on the case in which the majority of family members are both eligible and have primary school aged children. In these networks, Progresa leads to a relatively large increase in resources per household. In such families, connected households with and without primary school aged children are both sensitive on the margin to the total inflow of resources to the family network.

Taken together, the results help rule out other mechanisms behind why families matter. For example one alternative hypothesis would be that isolated households are not aware of the program, while connected households may simply share information rather than resources within their family network. However villages in the evaluation sample are small - the average number of households in each is 45 . It is hard to conceive of a significant proportion of households remaining unaware of such a large scale policy intervention.

A second alternative explanation would be that the presence of extended family is correlated to membership of ejidos which grant access to communal land, an institution that can help enforce interlinked labour-credit contracts. This is not supported by the evidence because if families mattered through these other channels, we would not expect household responses to Progresa in terms of secondary school enrolment to depend on the extent to which other households in the family network were eligible, or the extent to which these eligible households received transfers specific to their primary school aged children. ${ }^{33}$

\section{Which Family Members Matter and Why?}

We now exploit the full richness of the constructed data on extended family links to shed light on which family members matter for connected households' response, and why. To do so, we estimate (4.1) for households with family link type- $j$ and show how their response to Progresa varies with two characteristics of the link - the eligibility status of the link, and the demographic composition of children in linked households. ${ }^{34}$

\footnotetext{
${ }^{33}$ In fact less than $13 \%$ of households report their occupation as 'ejidatar' at baseline, and this does not differ between connected and isolated households. This perhaps reflects that ejidos have been in decline since land titled reforms were introduced in 1992.

${ }^{34}$ For example, to understand whether the program response of household $h$ varies with the eligibility status of the brother of the head of household, we define our link variable, $L_{j h}$, to be equal to one if the head of household $h$ has brothers present in the village and at least one brother is himself eligible for Progresa transfers, and zero if brothers are present in the village but all are non-eligible.
} 


\subsection{Intra-generational Family Links}

Column 1a of Table 7 estimates how the treatment effects of Progresa vary with the presence and eligibility status of the same gender siblings of the head and spouse of household $h$ - namely the brother of the head of household, and the sister of his spouse. ${ }^{35}$ Column 1a shows that eligible households in treatment villages that have an eligible brother of the head present, namely the uncle of the children in household $h$, increase secondary enrolment rates significantly more than analogous eligible households with eligible brothers in control villages $\left(T T E^{1}>0\right)$. In contrast, there is no program response among eligible households with non-eligible brothers $\left(T T E^{0}=0\right)$. Column 1b shows a similar pattern of responses among households by the eligibility status of the sister of the spouse, namely the aunt of the children in household $h$. The fact that households respond only if both they and their sibling are eligible for Progresa transfers is consistent with there being few resources to redistribute within the family when other members of the extended family are not eligible for Progresa.

The next columns explore whether for a given eligibility status of the sibling, the demographic composition of children in the sibling's household affects the response of household $h$ to the program. This pins down whether there is a redistribution of unconditionally received transfers from households with primary school aged children to their eligible siblings. We therefore define the link variable, $L_{j h}$, to be equal to one if the head of household $h$ has an eligible brother that has secondary school aged children, and equal to zero if the head of household $h$ has eligible brothers that only have primary school aged children.

Column 2a shows households with eligible brothers of the head present significantly increase secondary enrolment relative to analogous households in control villages. Importantly, the magnitude of the response is more than twice as large if siblings receive largely unconditional transfers through only having primary school aged children. Column 2b shows a similar pattern of results when we consider how the response of households varies with the demographic composition of children in the eligible household of the sister of the spouse.

One concern is that households whose siblings have younger children may differ on unobservables to those whose siblings have older children, and such unobservables drive program responses. This is addressed in Columns $3 \mathrm{a}$ and $3 \mathrm{~b}$ that show, conditional on the sibling being non-eligible, the demographic composition of the children of siblings does not influence the response of household $h$. It is not therefore the case that households that have siblings with young children respond differently to the program per se. Rather it is the interaction of those siblings being eligible for Progresa, with siblings receiving unconditional transfers for the primary school enrolment of their children, that allows household $h$ to itself respond to Progresa.

\footnotetext{
${ }^{35}$ We focus on same gender siblings because, first, these household pairs are likely to be at similar stages of the life cycle and so more similar on observables than cross-gender sibling pairs still resident in the village. In particular secondary and primary school aged children are likely to be observed in both households. Second, as shown in Table 3, the proportion of households with same gender siblings is the same across treatment and control villages by eligibility - the same is not true for cross-gender sibling pairs.
} 
This is consistent with within family resource transfers taking place from eligible households with primary school aged children to the households of their eligible siblings with secondary school aged children. Such receiving households are likely to be on the margin of enrolling their children into secondary school.

Finally, the results also show the presence of siblings with secondary school aged children only influences program responses if those siblings are themselves eligible for Progresa. This evidence contradicts the hypotheses that siblings share any fixed costs of secondary school, or that behavior is driven by conformity or peer effects within siblings based on secondary school outcomes. This is because such mechanisms should operate independent of the eligibility status of sibling links.

On the other hand, the result may reflect that some portion of the transfers received for secondary school enrolment are also viewed as de facto unconditional cash transfers that can be redistributed within the family network. This is to be expected given - (i) baseline secondary enrolment rates of around 65\%; (ii) around $50 \%$ of households with secondary school aged children at baseline sending all of their children to secondary school. Hence we note that approximately $33 \%$ of eligible households with secondary school aged children receive de facto unconditional cash transfers related to these children, in comparison to $90 \%$ for eligible households with primary school aged children.

\subsection{Inter-generational Family Links}

We now explore how household behavior is shaped by the characteristics of those in the family network that are inter-generationally linked. We first consider the links between the head and spouse of household $h$ to their adult sons or daughters that head their own household $j$ in the village. These individuals correspond to the adult siblings of the children actually resident in household $h$. Given the age structure of these links, we consider how the program response of household $h$ in terms of secondary school enrolment rates varies with the eligibility status and the presence of young children in household $j$. The presence of young children matters if the resources available to be shared are those transfers received on a largely unconditional basis, such as those for primary school enrolment, or the attendance of children aged under five to local health clinics.

As with sibling links, Column 1a of Table 8 shows eligible households only respond to Progresa if their adult son is also eligible $\left(T T E^{1}>0, T T E^{0}=0\right)$. Column $1 \mathrm{~b}$ confirms this applies equally to adult daughters resident in the village. To pin down whether these responses reflect within family resource transfers from adult children to their parents, we note first that the adult son is himself unlikely to have secondary school aged children. We therefore estimate how the treatment effects vary in household $h$ with the demographic composition of children in the eligible households of their adult sons and daughters. Given the age profile of such households, we consider the influence of eligible adult child households that have primary 
school aged children versus those that have no primary school aged children and are thus eligible either because of the presence of very young children or a pregnant wife.

Columns $2 \mathrm{a}$ and $2 \mathrm{~b}$ show the response of households, in terms of secondary school enrolment, increases conditional on their adult sons and daughters being eligible, and irrespective of the demographic composition of children in their adult son and daughter's households. This suggests adult sons and daughters view both components - transfers conditional on the primary school enrolment of their children and those conditional on their attendance to health clinics as pure income transfers that can be redistributed within the family network.

Finally, we consider inter-generational links from the head and spouse to their parents namely, the paternal and maternal grandparents of the children in household $h$. Such elderly households can be eligible for a health component of the program where those aged over 60 are required to attend a clinic once per year. The results in Columns 3a and 3b show the response of households to the program are generally weaker in the presence of the paternal or maternal grandparents of the children. Unlike the other family links considered, this is the case irrespective of the eligibility status of the household in which the paternal or maternal grandparents reside. This may reflect the low monetary value of transfers such elderly households are eligible for [Skoufias 2005]. ${ }^{36}$

\section{Discussion}

We have presented evidence from the Progresa social assistance program on whether and how household behavior is influenced by the presence and characteristics of its extended family. Our central finding is that Progresa raises secondary enrolment only among eligible households that are embedded in extended family networks. Eligible but isolated households do not respond. Our results suggest a key channel through which the extended family influences household schooling choices relates to the redistribution of resources among family members to enable eligible family members to fully overcome the opportunity costs of enrolling their children into secondary school.

There are a number of common themes running throughout our analysis that we now bring to the fore. The first stems from the design feature of Progresa that transfers are provided directly to women. If this increases females' bargaining power, household behavior may be differentially influenced by the characteristics of the extended family of the wife relative to that of her husband. However, throughout the paper we find no evidence that the family links of the spouse are more influential than are the family links of her husband. The mechanism through which extended family affects household schooling behavior - resource sharing - is qualitatively

\footnotetext{
${ }^{36}$ The evaluation data contains limited information on pre-program transfers. We note that those households defined to be of older generations are more likely to report receiving transfers at baseline. This is consistent with evidence from the Mexican Family Life Survey that transfers tend to flow from younger generations to older generations in the family network.
} 
the same for both the head and spouse's family links. ${ }^{37}$

A second common theme is that there is little evidence of any indirect treatment effect of Progresa, namely that secondary enrolment rates among non-eligibles in the family network do not increase on average. This suggests either - (i) resources are not transferred from eligibles to non-eligibles in the network; (ii) the amounts transferred are small; (iii) non-eligibles do not themselves use these resources to increase secondary enrolment. ${ }^{38}$

To shed light on this, in a companion paper we develop and test a model of insurance in these villages using the constructed data on extended family networks. Using information on consumption expenditures and exploiting the Progresa intervention as an exogenous income shock, we find evidence of positive and significant TTEs and ITEs in consumption for households embedded in family networks, and no effect for isolated households. This is in line with connected households sharing risk within the extended family, and not with unrelated villagers. ${ }^{39}$

The final theme running throughout our analysis has been the interplay between the design of conditional cash transfer programs, the presence of extended family members, and household responses to the program. There are three policy implications of our findings for the design of such programs. First, if families share resources, how connected households respond to such policies on any given margin, will generally depend on the eligibility status of others in their network. The particular design features of Progresa also lead to the behavior of connected households to depend on the demographic composition of others in the family network. More generally, our findings highlight that ignoring the presence and characteristics of the extended family can lead to an incomplete understanding of the forces driving the behavioral responses of households to large scale policy interventions in developing country settings.

Second, in this setting the value of transfers conditional on secondary school enrolment is not sufficiently high to offset any potential loss in children's labor market earnings if they were

\footnotetext{
${ }^{37}$ This result does not however imply that female bargaining power or the distribution of resources within the household is unaltered by Progresa [Attanasio and Lechene 2002].

${ }^{38}$ Note that we do not find robust evidence of an effect of the program on the school enrolment of the average non-eligible. Spillover effects in schooling have been reported by Bobonis and Finan [2006] and Cattaneo and Lalive [2006]. These alternative findings may stem from methodological differences. For example, Bobonis and Finan [2006] and Cattaneo and Lalive [2006] match children over the waves of the data and consider changes in each individual's enrolment status. Cattaneo and Lalive [2006] focus on the effects of the program in its first year up to October 1998 (wave 3), and consider the enrolment among primary school aged children and those transiting from primary to secondary school. Bobonis and Finan [2006] consider changes in enrolment of those children that have completed primary school at baseline, and find such spillover effects predominantly among those in non-eligible households on the margin of being eligible. Taken together, these results suggest there may be heterogeneous spillover effects on non-eligibles, and heterogeneous effects on the children within non-eligibles. Whether extended families influence the nature of such spillovers remains a question for future research.

${ }^{39}$ These results build on those of Angelucci and De Giorgi [2006] who find there to be indirect effects on the consumption of non-eligibles in treatment villages. They present evidence that this occurs through the insurance and credit markets - households indirectly benefit from their neighbors higher income by receiving more transfers, by borrowing more when hit by a negative idiosyncratic shock, and by reducing their precautionary savings. Angelucci and De Giorgi [2006] and Gertler et al [2006] provide evidence that local food prices do not change significantly over time between treatment and control villages suggesting that any ITEs are not being driven by general equilibrium effects of Progresa.
} 
to enrol into full time secondary education. Our results suggest that the resources spent on Progresa could therefore be more efficiently targeted if the policy aim is to increase secondary school enrolment. In particular, if the program's entire budget were to be channelled into transfers conditional on secondary school enrolment - with no component conditioned on primary enrolment, and such that the value of transfers offset children's labor market earnings - then we would expect both isolated and connected households to increase their secondary enrolment rates. $^{40}$

Finally, our analysis has general implications for understanding the role of family networks in developing economies. Using data from over 22,000 households in 506 villages in rural Mexico, we have documented that $20 \%$ of couple headed households are isolated in that none of their extended family members are geographically proximate in the same village. The incidence of this type of isolatedness is therefore at least as high as the incidence of single headedness, which affects $15 \%$ of households in our data. While there exists a large literature on the effects of single headedness on household welfare, our data and results suggest the importance of designing future surveys to identify isolated households in other settings, and more generally, to establish the social ties between households in survey data. Such information can then be used to understand the effects of isolation and being part of geographically proximate kinship networks on household behavior and welfare. This forms the basis of a broad and challenging research agenda. ${ }^{41}$

\section{References}

[1] AKResh.R (2007) Risk, Network Quality, and Family Structure: Child Fostering Decisions in Burkina Faso, mimeo University of Illinois at Urbana-Champaign.

[2] Altonji.J.G, F.HAYAShi, And L.J.Kotlikoff (1992) "Is the Extended Family Altruistically Linked? Direct Tests Using Micro Data", American Economic Review 85: 1177-98.

[3] Altonji.J.G, F.hayashi, And L.J.kotlikoff (1997) "Parental Altruism and Inter Vivos Transfers: Theory and Evidence", Journal of Political Economy 105: 1121-66.

[4] Angelucci.m and G.De Giorgi (2006) "Indirect Effects of an Aid Program: How Do Liquidity Injections Affect Non-Eligibles' Consumption?", forthcoming American Economic Review.

\footnotetext{
${ }^{40}$ Todd and Wolpin [2006] develop and test a structural dynamic model of the schooling and fertility effects of Progresa. They find the policy as currently designed increases years of schooling on average by .5 years. They then estimate the effect of a revenue neutral reform that eliminates transfers to children in grades 3 to 5 and increasing transfers to those in grades 6 to 9 by around $50 \%$. They find such a reform would increase average completed schooling by an additional .1 years. Attanasio et al [2005] conduct a similar experiment and also find larger effects on secondary enrolment of such revenue neutral policy alternatives.

${ }^{41}$ Studies that have collected detailed information on the structure of family and other networks in village economy settings have provided important insights on the role of social networks in learning about agriculture in Ghana [Conley and Udry 2007], and child fostering in Burkina Faso [Akresh 2007].
} 
[5] Attanasio.o And V.lechene (2002) "Tests of Income Pooling in Household Decisions", Review of Economic Dynamics 5: 720-48.

[6] attanasio.o, C.meghir, And A.Santiago (2005), Education Choices in Mexico: Using a Structural Model and a Randomised Experiment to Evaluate Progresa, IFS Working Paper.

[7] BANERJEE.A AND A.NEWMAN (1998) "Information, the Dual Economy, and Development", Review of Economic Studies 65: 631-53.

[8] BeCKer.g.s (1981) A Treatise on the Family, Cambridge: Harvard University Press.

[9] Behrman.J.R And M.rosenzWeig (2006) "Parental Wealth and Adult Children's Welfare in Marriage", Review of Economics and Statistics 88: 496-509.

[10] Behrman.J.R, P.sengupta, And P.TOdD (2005), "Progressing Through Progresa: An Impact Assessment of a School Subsidy Experiment in Rural Mexico", Economic Development and Cultural Change 54: 237-76.

[11] Bobonis.g And F.Finan (2006) Endogenous Peer Effects in School Participation, mimeo, University of Toronto.

[12] CAttaneo.A And R.LAlive (2006) "Social Interactions in Schooling Decisions", forthcoming Review of Economics and Statistics.

[13] CHiappori.P.A (1988) "Rational Household Labor Supply", Econometrica 56: 63-90.

[14] COnley.T And C.UdRY (2007) Learning About a New Technology: Pineapple in Ghana, mimeo Yale University.

[15] COX.D And G.JAkubson (1995) "The Connection Between Public Transfers and Private Interfamily Transfers", Journal of Public Economics 57: 129-67.

[16] DeAton.a (1992) "Saving and Income Smoothing in Côte D'Ivoire", Journal of African Economies 1: 1-24.

[17] DERCON.S AND P.KRISHnAN (2000) "In Sickness and in Health: Risk Sharing Within Households in Rural Ethiopia", Journal of Political Economy 108: 688-727.

[18] FAFCHAmPs.m AND S.Lund (2003) "Risk-sharing Networks in Rural Philippines", Journal of Development Economics 71: 261-87.

[19] GerTler.P, S.MARTinez, AND M.RUBio-Codina (2006) Investing Cash Transfers to Raise Long-Term Living Standards, mimeo University of California Berkeley. 
[20] LA FERRARA.E (2003) "Kin groups and Reciprocity: A Model of Credit Transactions in Ghana", American Economic Review 93: 1730-51.

[21] LigON.E (1998) "Risk-Sharing and Information in Village Economies", Review of Economic Studies 65: 847-64.

[22] LOURY.L.D (2006) "All in the Extended Family: Effects of Grandparents, Aunts, and Uncles on Educational Attainment", American Economic Review Papers and Proceedings 96: $275-8$.

[23] MAnSER.m And M.Brown (1980) "Marriage and Household Decision Theory - A Bargaining Analysis", International Economic Review 21: 21-34.

[24] MCELROy.m And M.HORnEy (1981) "Nash-bargained Decisions: Towards a Generalization of the Theory of Demand", International Economic Review 22: 333-49.

[25] MUnshi.K And Rosenzweig.m (2005) Why is Mobility in India so Low? Social Insurance, Inequality, and Growth, mimeo Brown University.

[26] RosenzWeig.M.R (1988) "Risk, Implicit Contracts and the Family in Rural Areas of Low Income Countries", Economic Journal 98: 1148-70.

[27] ROSEnZWEig.M.R AND O.STARK (1989) "Consumption Smoothing, Migration, and Marriage: Evidence From Rural India", Journal of Political Economy 97: 905-26.

[28] Schultz.T.P (2004) "School Subsidies for the Poor: Evaluating the Mexican Progresa Poverty Program", Journal of Development Economics 74: 199-250.

[29] Skoufias.e (2005) Progresa and Its Impacts on the Human Capital and Welfare of Households in Rural Mexico: A Synthesis of the Results of an Evaluation by IFPRI, Research Report 139, Washington D.C.: International Food Policy Research Institute.

[30] TODD.P AND K.I.WOLPIN (2006) "Assessing the Impact of a School Subsidy Program in Mexico: Using a Social Experiment to Validate a Dynamic Behavioral Model of Child Schooling and Fertility", American Economic Review 96: 1384-1417.

[31] TOWnsEnd.R (1994) "Risk and Insurance in Village India", Econometrica 62: 539-91.

[32] UDRY.C (1994) 'Risk and Insurance in a Rural Credit Market: An Empirical Investigation in Northern Nigeria', Review of Economic Studies 61: 495-526.

[33] WEISS.Y AND R.J.WILlis (1985) "Children as Collective Goods and Divorce Settlements", Journal of Labor Economics 3: 268-92. 
Table 1: The Number of Extended Family Links, by Type of Link

\section{Couple Headed Households}

Mean, standard error in parentheses clustered by village

\begin{tabular}{|c|c|c|c|c|c|c|c|c|c|c|}
\hline & \multicolumn{10}{|c|}{ Outside the Household and in the Village } \\
\hline & \multicolumn{2}{|c|}{ Parent } & \multicolumn{2}{|c|}{ Children Aged 0-16 } & \multicolumn{2}{|c|}{ Adult Children } & \multicolumn{2}{|c|}{$\underline{\text { Siblings }}$} & \multicolumn{2}{|c|}{ All } \\
\hline & Connected & Isolated & Connected & Isolated & Connected & Isolated & Connected & Isolated & Connected & Isolated \\
\hline \multirow[t]{2}{*}{ From head of household to: } & .461 & - & - & - & .652 & - & 2.23 & - & 3.34 & - \\
\hline & $(.010)$ & & & & $(.066)$ & & $(.111)$ & & $(.164)$ & \\
\hline \multirow[t]{5}{*}{ From spouse of household to: } & .250 & - & - & - & .652 & - & 1.63 & - & 2.54 & - \\
\hline & $(.007)$ & & & & $(.066)$ & & (.103) & & $(.160)$ & \\
\hline & \multicolumn{10}{|c|}{ Inside the Household } \\
\hline & \multicolumn{2}{|c|}{ Parent } & \multicolumn{2}{|c|}{$\underline{\text { Children Aged 0-16 }}$} & \multicolumn{2}{|c|}{ Adult Children } & \multicolumn{2}{|c|}{$\underline{\text { Siblings }}$} & \multicolumn{2}{|c|}{ All } \\
\hline & Connected & Isolated & Connected & Isolated & Connected & Isolated & Connected & Isolated & Connected & Isolated \\
\hline \multirow[t]{2}{*}{ From head of household to: } & .062 & .079 & 3.23 & 3.10 & .821 & .787 & .033 & .052 & 4.15 & 4.02 \\
\hline & $(.003)$ & $(.006)$ & $(.027)$ & $(.043)$ & $(.015)$ & $(.021)$ & $(.002)$ & $(.007)$ & $(.035)$ & $(.056)$ \\
\hline \multirow[t]{2}{*}{ From spouse of household to: } & .018 & .021 & 3.23 & 3.10 & .821 & .787 & .013 & .017 & 4.09 & 3.93 \\
\hline & $(.001)$ & $(.003)$ & $(.027)$ & $(.043)$ & $(.015)$ & $(.021)$ & $(.001)$ & $(.003)$ & $(.034)$ & $(.054)$ \\
\hline
\end{tabular}


Table 2: Probability of an Extended Family Link

\section{Couple Headed Households}

Mean, standard errors in parentheses clustered by village

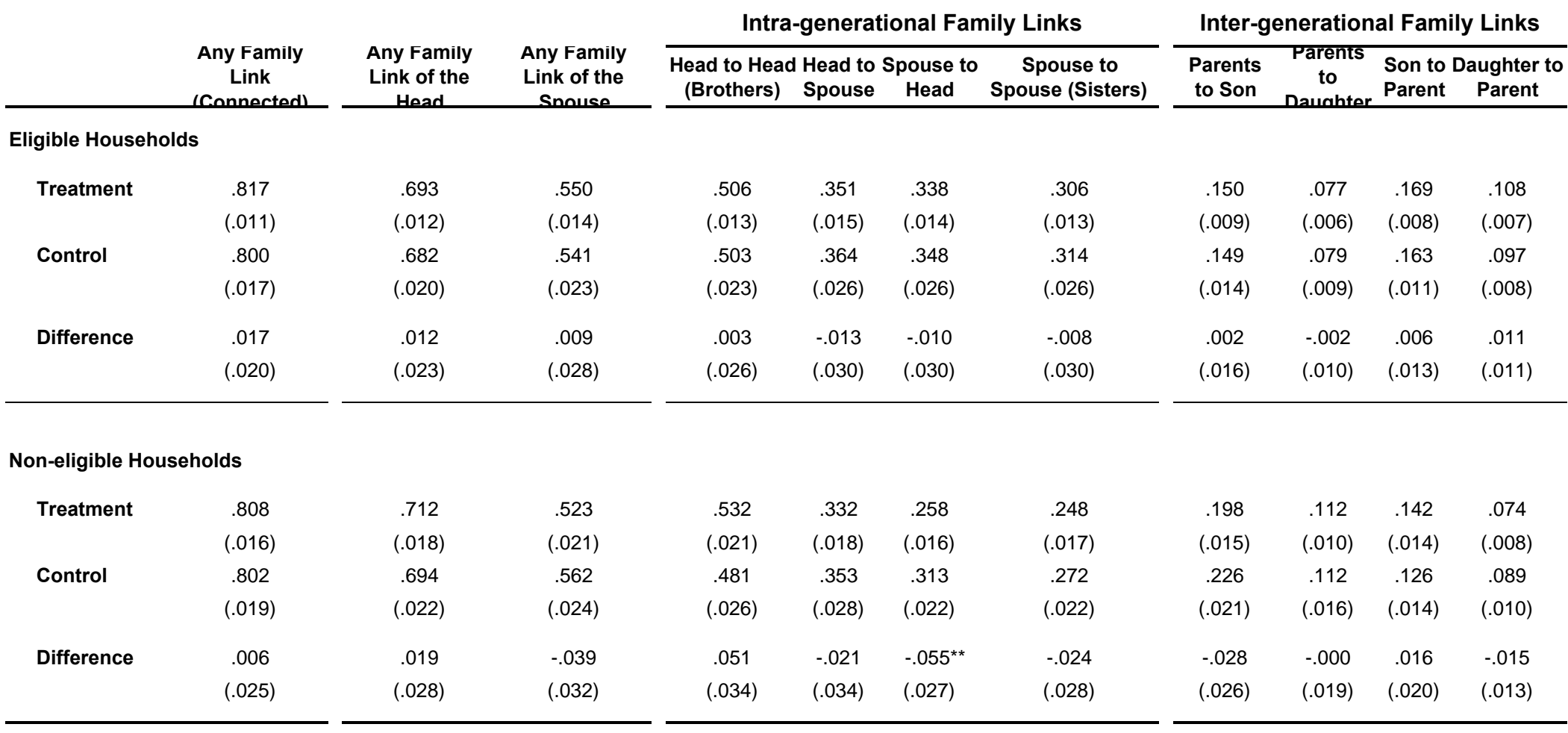

Notes: $* * *$ denotes significance at $1 \%,{ }^{*}$ at $5 \%$, and * at $10 \%$. Standard errors are clustered by village. The sample is restricted to couple headed households that can be tracked over the first and third Progresa wave Means and differences are reported for those households that have secondary school age children (aged 11 to 16 ) in the baseline survey of October 1997. The standard errors on the differences are calculated from running a corresponding OLS regression, which allows for the error terms to be clustered by village. 


\section{Table 3: Family Network Descriptives}

Means, standard deviation between villages in parentheses, standard deviation within villages in brackets

\begin{tabular}{|c|c|c|c|c|c|c|c|}
\hline Treatment Villages & $\begin{array}{l}\text { Size of Global } \\
\text { Family Network }\end{array}$ & $\begin{array}{l}\text { Network Size/Number of } \\
\text { Households in Village }\end{array}$ & Diameter & $\begin{array}{l}\text { Share that are } \\
\text { Eligible }\end{array}$ & $\begin{array}{l}\text { Share With Primary School } \\
\text { Aged Children at Baseline }\end{array}$ & $\begin{array}{l}\text { Share With Secondary School } \\
\text { Aged Children at Baseline }\end{array}$ & $\begin{array}{l}\text { Average Value of Potential } \\
\text { Transfers Households in Network } \\
\text { are Eligible for (March 1998, pesos) }\end{array}$ \\
\hline Mean & 7.66 & .169 & 2.42 & .518 & .480 & .480 & 746 \\
\hline Standard deviation between villages & $(.249)$ & $(.153)$ & $(1.20)$ & $(.233)$ & $(.150)$ & $(.139)$ & (181) \\
\hline Standard deviation within villages & [.153] & [.153] & [2.14] & [.259] & {$[.262]$} & {$[.263]$} & [281] \\
\hline Control Villages & $\begin{array}{l}\text { Size of Global } \\
\text { Family Network }\end{array}$ & $\begin{array}{l}\text { Network Size/Number of } \\
\text { Households in Village }\end{array}$ & Diameter & $\begin{array}{l}\text { Share that are } \\
\text { Eligible }\end{array}$ & $\begin{array}{l}\text { Share With Primary School } \\
\text { Aged Children at Baseline }\end{array}$ & $\begin{array}{l}\text { Share With Secondary School } \\
\text { Aged Children at Baseline }\end{array}$ & $\begin{array}{l}\text { Average Value of Potential } \\
\text { Transfers Households in Network } \\
\text { are Eligible for (March 1998, pesos) }\end{array}$ \\
\hline Mean & 7.92 & .163 & 2.51 & .525 & .484 & .491 & 756 \\
\hline Standard deviation between villages & $(.230)$ & $(.141)$ & $(1.14)$ & $(.249)$ & $(.145)$ & $(.139)$ & (188) \\
\hline Standard deviation within villages & [.155] & [.155] & [2.07] & [.229] & [.252] & {$[.258]$} & [297] \\
\hline
\end{tabular}

Notes: The sample is restricted to households that can be tracked over the first and third Progresa waves. There is one observation per family network so that each network has the same weight irrespective of the number of households within it. There are 1379 family networks in treatment villages covering 10559 households. There are 817 family networks in control villages covering 6471 households. The size of the network is the number of households in the network. The diameter of the networks is the longest

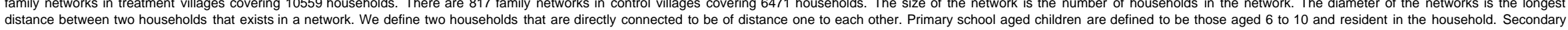
school aged children are defined to be those aged 11 to 16 and resident in the household. The average value of potential transfers households in the network are eligible for, are calculated among eligible households only. The standard deviations between and within villages take account of the fact that there are an unequal number of familv networks in each villaae. 


\section{Table 4: Descriptive Evidence on Enrolment Rates}

\section{Couple Headed Households}

\section{Mean, standard errors in parentheses clustered by village}

Secondary School Enrolment Rates (children aged 11 to 16)

\begin{tabular}{ccc}
\multicolumn{2}{c}{ Eligibles, by Village Type } \\
\hline Control $\quad$ Treatment & $\begin{array}{c}\text { All Households } \\
\text { Difference in } \\
\text { Difference }\end{array}$ \\
October 1997 October 1997 & $\begin{array}{c}\text { Ond } \\
\text { Din }\end{array}$
\end{tabular}

\begin{tabular}{lccc}
\hline All children & .651 & .654 & $.069^{\star \star \star}$ \\
& $(.016)$ & $(.012)$ & $(.016)$ \\
Boys & .681 & .685 & $.043^{\star \star}$ \\
& $(.017)$ & $(.013)$ & $(.022)$ \\
\multirow{3}{*}{ Girls } & .603 & .612 & $.102^{\star \star \star}$ \\
& $(.018)$ & $(.014)$ & $(.022)$ \\
& & & \\
\hline
\end{tabular}

\begin{tabular}{|c|c|c|c|}
\hline Connected & Isolated & Connected & Isolated \\
\hline October 1997 & October 1997 & $\begin{array}{l}\text { Difference in } \\
\text { Difference }\end{array}$ & $\begin{array}{l}\text { Difference in } \\
\text { Difference }\end{array}$ \\
\hline .653 & .654 & $.083^{\star \star \star}$ & .001 \\
\hline$(.011)$ & $(.015)$ & $(.017)$ & $(.031)$ \\
\hline .681 & .698 & $.044^{*}$ & .040 \\
\hline$(.012)$ & $(.016)$ & $(.023)$ & $(.047)$ \\
\hline .608 & .610 & $.131^{\star \star \star}$ & -.030 \\
\hline$(.012)$ & $(.019)$ & $(.024)$ & $(.044)$ \\
\hline
\end{tabular}

Primary School Enrolment Rates (children aged 6 to 10)

Notes: *** denotes significance at $1 \%, * *$ at $5 \%$, and * at $10 \%$. The sample is restricted to couple headed households that can be tracked over the first and third Progresa waves. A household's secondary school enrolment rate is defined to be the fraction of children aged 11 to 16 resident in the household that are full-time enrolled in secondary school at the time of the survey. A household's primary school enrolment rate is defined to be the fraction of children aged 6 to 10 be the fraction of children aged 11 to 16 resident in the household that are full-time enrolled in secondary school at the time of the survey. A household's primary school enrolment rate is defined to be the fraction of children aged 6 to 10
resident in the household that are full-time enrolled in primary school at the time of the survey. In the left hand panel, the difference in difference is defined to be the difference in enrolment rates between households in treatment and control villages in November 1999, minus the corresponding difference at baseline in October 1997. In the centre and right hand panels, this difference in difference is reported for connected and isolated households separately. Standard errors on the differences are derived from an OLS regression, estimated on eligible and non-eligibles separately, of school enrolment rates on a dummy equal to one for Progresa villages and zero otherwise. Standard errors are clustered by village. 
Table 5: Baseline Estimates

Dependent Variable (Columns 1-4b): Change in Household's Secondary School Enrolment Rate (November 1999 - October 1997) Dependent Variable (Column 5): Household's Secondary School Enrolment Rate at Baseline (October 1997)

OLS regression estimates, standard errors are clustered by village

\begin{tabular}{|c|c|c|c|c|c|c|c|}
\hline \multicolumn{3}{|c|}{ All Children } & Boys & Girls & Boys & Girls & \multirow{3}{*}{$\begin{array}{c}\text { All Children } \\
\text { Secondary Enrolment } \\
\text { Rate at Baseline } \\
\text { (October 1997) }\end{array}$} \\
\hline Standard & Family Links & Interactions & Interactions & Interactions & High Ad & e Villages & \\
\hline (1) & (2a) & (2b) & (3a) & (3b) & (4a) & (4b) & \\
\hline
\end{tabular}

\begin{tabular}{ll} 
& $(\mathbf{1})$ \\
\hline TTE & $.078^{\star \star \star}$ \\
& $(.016)$ \\
ITE & -.015 \\
& $(.026)$ \\
TTE [connected] &
\end{tabular}

TTE [isolated]

ITE [connected]

ITE [isolated]

$\begin{array}{ll}.093^{\star \star \star} & .092^{\star \star \star} \\ (.017) & (.018) \\ .009 & .006 \\ (.032) & (.032) \\ -.016 & -.027 \\ (.028) & (.030) \\ -.007 & -.012 \\ (.061) & (.061)\end{array}$

$\begin{array}{cl}.055^{\star *} & .126^{* * *} \\ (.025) & (.026) \\ .041 & -.035 \\ (.048) & (.046) \\ .008 & -.035 \\ (.042) & (.046) \\ .020 & -.006 \\ (.083) & (.077)\end{array}$

$\begin{array}{cc}.040 & .095^{\star \star \star} \\ (.028) & (.029) \\ .038 & -.013 \\ (.056) & (.050) \\ .005 & -.020 \\ (.049) & (.050) \\ .056 & .019 \\ (.089) & (.080)\end{array}$

Average poverty index of households in

the extended family / 100

\begin{tabular}{|c|c|c|c|}
\hline$\Delta$ TTE & & $\begin{array}{l}.084^{\star \star} \\
(.035)\end{array}$ & $\begin{array}{l}.086^{\star \star} \\
(.036)\end{array}$ \\
\hline$\Delta \mathrm{ITE}$ & & $\begin{array}{l}-.009 \\
(.065)\end{array}$ & $\begin{array}{l}-.015 \\
(.065)\end{array}$ \\
\hline Observations & 6227 & 6227 & 6227 \\
\hline
\end{tabular}

\begin{tabular}{cl}
\hline .013 & $.161^{\star \star \star}$ \\
$(.052)$ & $(.052)$ \\
-.012 & -.029 \\
$(.093)$ & $(.085)$ \\
\hline 3947 & 3760
\end{tabular}

\begin{tabular}{cc} 
& \\
\hline .002 & $.107^{\star}$ \\
$(.061)$ & $(.057)$ \\
-.052 & -.039 \\
$(.102)$ & $(.091)$ \\
\hline 2844 & 2765 \\
\hline
\end{tabular}

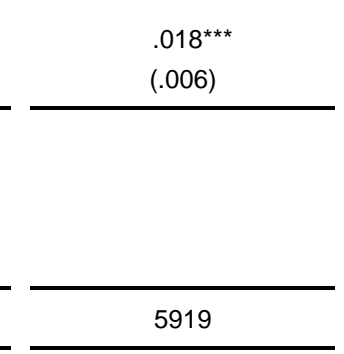

Notes: ${ }^{* \star *}$ denotes significance at $1 \%, * *$ at $5 \%$, and ${ }^{*}$ at $10 \%$. The sample is restricted to couple headed households that can be tracked over the first and third Progresa waves. Standard errors are clustered by village. A household's secondary school enrolment rate is defined to be the fraction of children aged 11 to 16 resident in the household that are full-time enrolled in school at the time of the survey. In Columns 2a onwards the link variable is defined to be equal to one if household $\mathrm{h}$ has any family links in the village, and zero otherwise. All specifications also control for the following - the husband's age, literacy, whether he speaks an indigenous language, the spouse's age, literacy, whether she speaks an indigenous language, the household poverty index, whether the household owns any land, the number of individuals in the household at baseline, the number of households in the village, the share of households in the village that are eligible, the marginality index for the village, regional fixed effects, and the village level enrolment rate at baseline among eligible and non-eligible households. In Columns $2 b$ to $4 \mathrm{~b}$ the effects of the following controls are also allowed to vary with eligibility status, Progresa, and the interaction of the two - whether the head's (spouse's) age is above or below the median among couple headed households, whether the head (spouse) is literate, whether the household owns land, whether the household size at baseline is above or below the median among couple headed households, and the village level enrolment rates at the baseline among eligible and non-eligible households. The samples in Columns $4 \mathrm{a}$ and $4 \mathrm{~b}$ are restricted to villages that have above the median level of adult wages as recorded in October 1998. In Column 5 the sample and the same set of controls as in Column 1 are included. The household poverty index increases as the household has higher permanent income. 
Table 6: Extended Families, Transfers, and the Response to Progresa

Dependent Variable: Change in Household's Secondary School Enrolment Rate (November 1999 - October 1997)

OLS regression estimates, standard errors are clustered by village

\begin{tabular}{|c|c|c|c|c|}
\hline \multirow[b]{3}{*}{ Households With Primary School Aged Children } & \multirow{2}{*}{$\frac{\text { Isolated }}{\text { Own Transfer }}$} & \multirow{2}{*}{$\begin{array}{c}\text { Connected } \\
\begin{array}{c}\text { Own and Family } \\
\text { Transfer }\end{array}\end{array}$} & \multicolumn{2}{|c|}{$\begin{array}{l}\text { Connected Households, Varying Characteristics } \\
\text { of the Local Family Network }\end{array}$} \\
\hline & & & $\begin{array}{l}\text { Minority of Family is Eligible and } \\
\text { Has Primary School Aged Children }\end{array}$ & $\begin{array}{l}\text { Majority of Family is Eligible and } \\
\text { Has Primary School Aged Children }\end{array}$ \\
\hline & (1) & (2) & (3) & (4) \\
\hline \multirow[t]{2}{*}{ TTE [evaluated at mean of own transfer] } & -.010 & & & \\
\hline & $(.043)$ & & & \\
\hline \multirow[t]{2}{*}{ TTE [evaluated at mean of own + family transfer] } & & $.093^{* \star *}$ & $.133^{\star \star \star}$ & $.076^{\star *}$ \\
\hline & & $(.021)$ & $(.035)$ & $(.030)$ \\
\hline \multirow[t]{2}{*}{ Evaluated at mean of own transfer, family transfer $=0$} & & & .045 & \\
\hline & & & $(.030)$ & \\
\hline Observations & 659 & 3180 & 1622 & 1558 \\
\hline \multicolumn{5}{|l|}{ Households With No Primary School Aged Children } \\
\hline \multirow[t]{2}{*}{ TTE [evaluated at mean of own transfer] } & .077 & & & \\
\hline & $(.086)$ & & & \\
\hline \multirow[t]{2}{*}{ TTE [evaluated at mean of own + family transfer] } & & $.119^{\star \star \star}$ & .053 & $.116^{*}$ \\
\hline & & $(.044)$ & $(.079)$ & $(.067)$ \\
\hline \multirow[t]{2}{*}{ Evaluated at mean of own transfer, family transfer $=0$} & & & .096 & \\
\hline & & & $(.077)$ & \\
\hline Observations & 194 & 814 & 457 & 357 \\
\hline
\end{tabular}

Notes: ${ }^{* \star}$ denotes significance at $1 \%, * \star$ at $5 \%$, and $*$ at $10 \%$. The sample is restricted to eligible couple headed households that can be tracked over the first and third Progresa waves. Standard errors are clustered by village. A household's secondary school enrolment rate is defined to be the fraction of children aged 11 to 16 resident in the household that are full-time enrolled in school at the time of the survey. For the own transfer effects, the value of potential transfers to the households is evaluated at the mean of the distribution of such transfers in October 1998 among all eligible couple headed households that have secondary school aged children. In Column 2 onwards, the family refers to the local family network at degree one to the household. The value of potential transfers to the local family network that is eligible is evaluated at the mean of the distribution of such transfers in October 1998 among the local family network (excluding the household itself) of all connected eligible couple headed households that have secondary school aged children. All specifications also control for the following - the husband's age, years of schooling, literacy, whether he speaks an indigenous language, the spouse's age, years of schooling, literacy, whether she speaks an indigenous language, the household poverty index, the number of individuals in the household at baseline, the number of households in the village, the share of households in the village that are eligible, the marginality index for the village, regional fixed effects, and the village level enrolment rate at baseline among eligible and non-eligible households. In all columns the effects of the following controls are also allowed to vary with Progresa - whether the head's (spouse's) age is above or below the median among couple headed households, whether the head (spouse) is literate, whether the household owns land, whether the household size at baseline is above or below the median among couple headed households, and the village level enrolment rates at the baseline among eligible and non-eligible households. 
Table 7: Schooling and Eligibility Status of Intra-generational Family Links

Dependent Variable: Change in Household's Secondary School Enrolment Rate (November 1999 - October 1997)

OLS regression estimates, standard errors are clustered by village

Inter-generational Family Link Type:

\begin{tabular}{|c|c|c|c|c|c|}
\hline Brothers & Sisters & Brothers & Sisters & Brothers & Sisters \\
\hline $\begin{array}{c}\text { Father to } \\
\text { Uncle }\end{array}$ & $\begin{array}{c}\text { Mother to } \\
\text { Aunt }\end{array}$ & $\begin{array}{c}\text { Father to } \\
\text { Uncle }\end{array}$ & $\begin{array}{c}\text { Mother to } \\
\text { Aunt }\end{array}$ & $\begin{array}{c}\text { Father to } \\
\text { Uncle }\end{array}$ & $\begin{array}{c}\text { Mother to } \\
\text { Aunt }\end{array}$ \\
\hline (1a) & (1b) & (2a) & (2b) & (3a) & $(3 b)$ \\
\hline
\end{tabular}

TTE [linked household is eligible]

$\begin{array}{ll}.134^{\star \star \star} & .106^{\star \star \star} \\ (.038) & (.040) \\ -.010 & .061 \\ (.046) & (.058)\end{array}$

TTE [linked household is eligible and has secondary school age children]

TTE [linked household is eligible and has only primary school age children]

TTE [linked household is non-eligible and has secondary school age children]

TTE [linked household is non-eligible and has only primary school age children]

$\begin{array}{ll}.096^{\star} & .139 \star \star \star \\ (.052) & (.053) \\ .215^{\star \star \star} & .183^{\star \star} \\ (.075) & (.085)\end{array}$

\begin{tabular}{llllllll} 
& $(.176)$ & & & & & & \\
\hline Observations & 1366 & 1064 & 631 & 524 & 369 & 302
\end{tabular}

Notes: $* \star *$ denotes significance at $1 \%$ ** at $5 \%$, and * at $10 \%$. The sample is restricted to couple headed households that can be tracked over the first and third Progresa waves. Standard errors are

Notes: denotes significance at $1 \%, \star \star$ at $5 \%$, and $\star$ at $10 \%$. The sample is resticted to couple headed households that can be tracked over the first and third Progresa waves. Standard errors are clustered by village. A household's secondary school enrolment rate is defined to be the fraction of children aged 11 to 16 resident in the household that are full-time enrolled in school at the time of the survey. All specifications also control for the following - the husband's age, years of schooling, literacy, whether he speaks an indigenous language, the spouse's age, years of schooling, literacy, whether she speaks an indigenous language, the household poverty index, the number of individuals in the household at baseline, the number of households in the village, the share of households in the villaqe that are eliqible, the marqinality index for the villaqe, reqional fixed effects, and the villaqe level enrolment rate at baseline amonq eliqible and non-eliqible households. 


\section{Table 8: Eligibility Status of Inter-generational Family Links}

Dependent Variable: Change in Household's Secondary School Enrolment Rate (November 1999 - October 1997)

OLS regression estimates, standard errors are clustered by village

\begin{tabular}{|c|c|c|c|c|c|c|}
\hline Inter-generational Link Type: & Parents to Son & $\begin{array}{l}\text { Parents to } \\
\text { Daughter }\end{array}$ & Parents to Son & $\begin{array}{l}\text { Parents to } \\
\text { Daughter }\end{array}$ & Son to Parents & $\begin{array}{l}\text { Daughter to } \\
\text { Parents }\end{array}$ \\
\hline $\begin{array}{l}\text { Relationship to secondary school age children } \\
\text { in household } \mathrm{h} \text { : }\end{array}$ & $\begin{array}{c}\text { Father to Adult } \\
\text { Brother } \\
\text { (1a) }\end{array}$ & $\begin{array}{c}\text { Mother to Adult } \\
\text { Sister } \\
\text { (1b) }\end{array}$ & $\begin{array}{c}\text { Father to Adult } \\
\text { Brother } \\
\text { (2a) }\end{array}$ & $\begin{array}{c}\text { Mother to Adult } \\
\text { Sister } \\
\text { (2b) }\end{array}$ & $\begin{array}{c}\text { Father to } \\
\text { Paternal } \\
\text { Grandparents } \\
\text { (3a) }\end{array}$ & $\begin{array}{c}\text { Mother to } \\
\text { Maternal } \\
\text { Grandparents } \\
\text { (3b) }\end{array}$ \\
\hline TTE [linked household is eligible] & $\begin{array}{l}.206^{* * *} \\
(.045)\end{array}$ & $\begin{array}{l}.173^{* * *} \\
(.054)\end{array}$ & & & $\begin{array}{l}.085 \\
(.053)\end{array}$ & $\begin{array}{r}.102^{*} \\
(.060)\end{array}$ \\
\hline TTE [linked household is non-eligible] & $\begin{array}{c}.078 \\
(.077)\end{array}$ & $\begin{array}{c}.088 \\
(.120)\end{array}$ & & & $\begin{array}{c}.001 \\
(.037)\end{array}$ & $\begin{array}{l}.077^{*} \\
(.046)\end{array}$ \\
\hline $\begin{array}{l}\text { TTE [linked household is eligible and has } \\
\text { primary school aged children] }\end{array}$ & & & $\begin{array}{l}.148^{\star \star} \\
(.063)\end{array}$ & $\begin{array}{l}.171^{\star *} \\
(.078)\end{array}$ & & \\
\hline $\begin{array}{l}\text { TTE [linked household is eligible and has no } \\
\text { primary school aged children] }\end{array}$ & & & $\begin{array}{l}.269^{\star \star \star} \\
(.060)\end{array}$ & $\begin{array}{l}.196 * * \\
(.083)\end{array}$ & & \\
\hline Observations & 965 & 499 & 690 & 384 & 1028 & 649 \\
\hline
\end{tabular}

Notes: ${ }^{* \star}$ denotes significance at $1 \%, * \star$ at $5 \%$, and ${ }^{*}$ at $10 \%$. The sample is restricted to couple headed households that can be tracked over the first and third Progresa waves. Standard errors are clustered by village. A household's secondary school enrolment rate is defined to be the fraction of children aged 11 to 16 resident in the household that are full-time enrolled in school at the time of the survey. All specifications also control for the following - the husband's age, years of schooling, literacy, whether he speaks an indigenous language, the spouse's age, years of schooling, literacy, whether she speaks an indigenous language, the household poverty index, the number of individuals in the household at baseline, the number of households in the village, the share of households in the village that are eligible, the marginality index for the village, regional fixed effects, and the village evel enrolment rate at baseline among eligible and non-eligible households. 


\section{Figure 1: Family Tree}

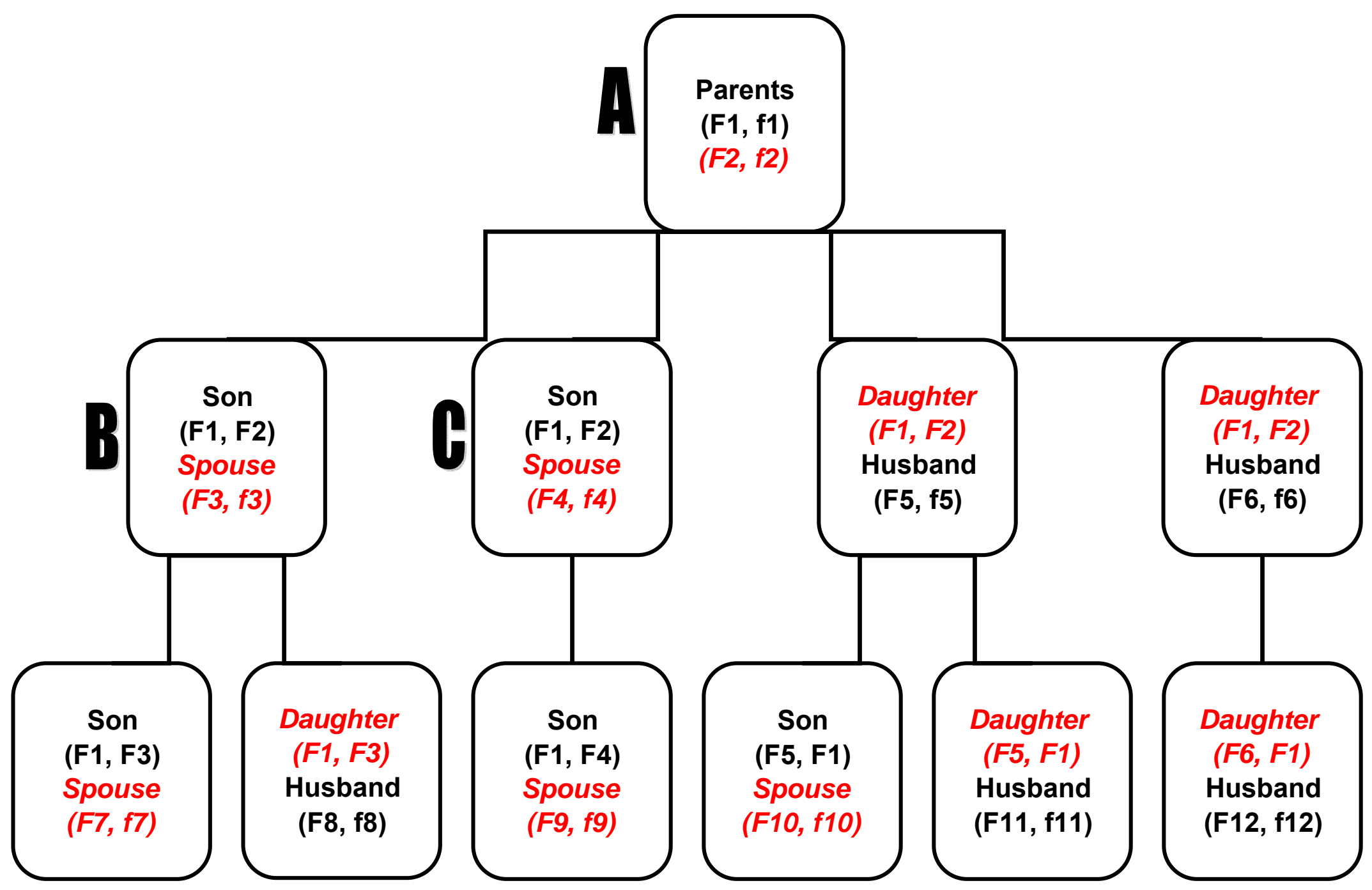

Notes: We use the convention that the head's surnames are written in standard (black) font, and those of his wife are written in (red) italics. Paternal surnames are indicated in upper case (F1, F2) and maternal surnames are indicated in lower case $(f 1, f 2)$. First names are not shown as they are not relevant for the construction of extended family ties. Each household in the family tree is assumed to be couple headed purely to ease the exposition. 
Figure 2A: Potential Transfers in Eligible Isolated and Connected Households

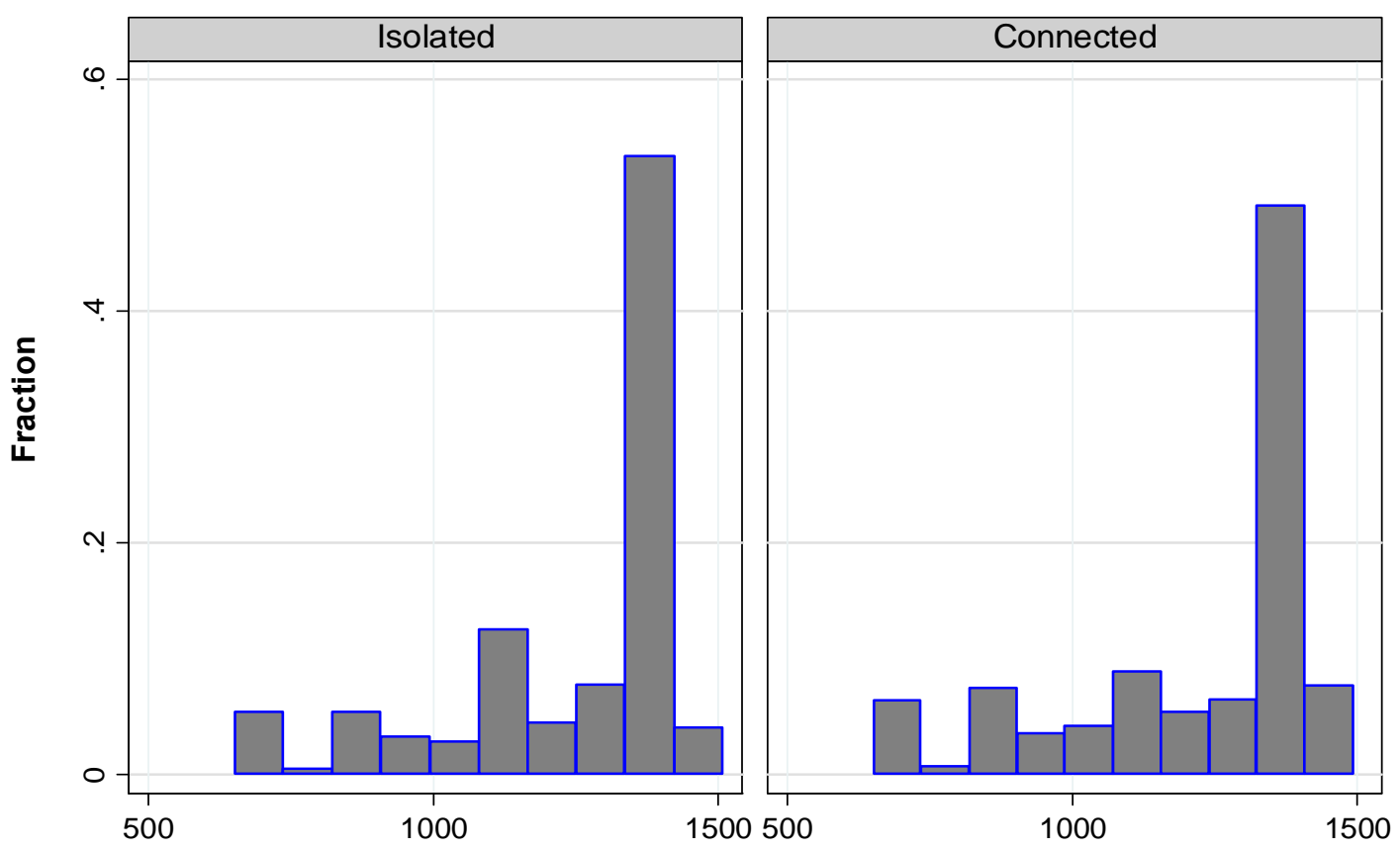

Value of Transfers Household is Eligible for (October 1998, pesos)

Figure 2B: Potential Transfers in Eligible Households and Their Family Network

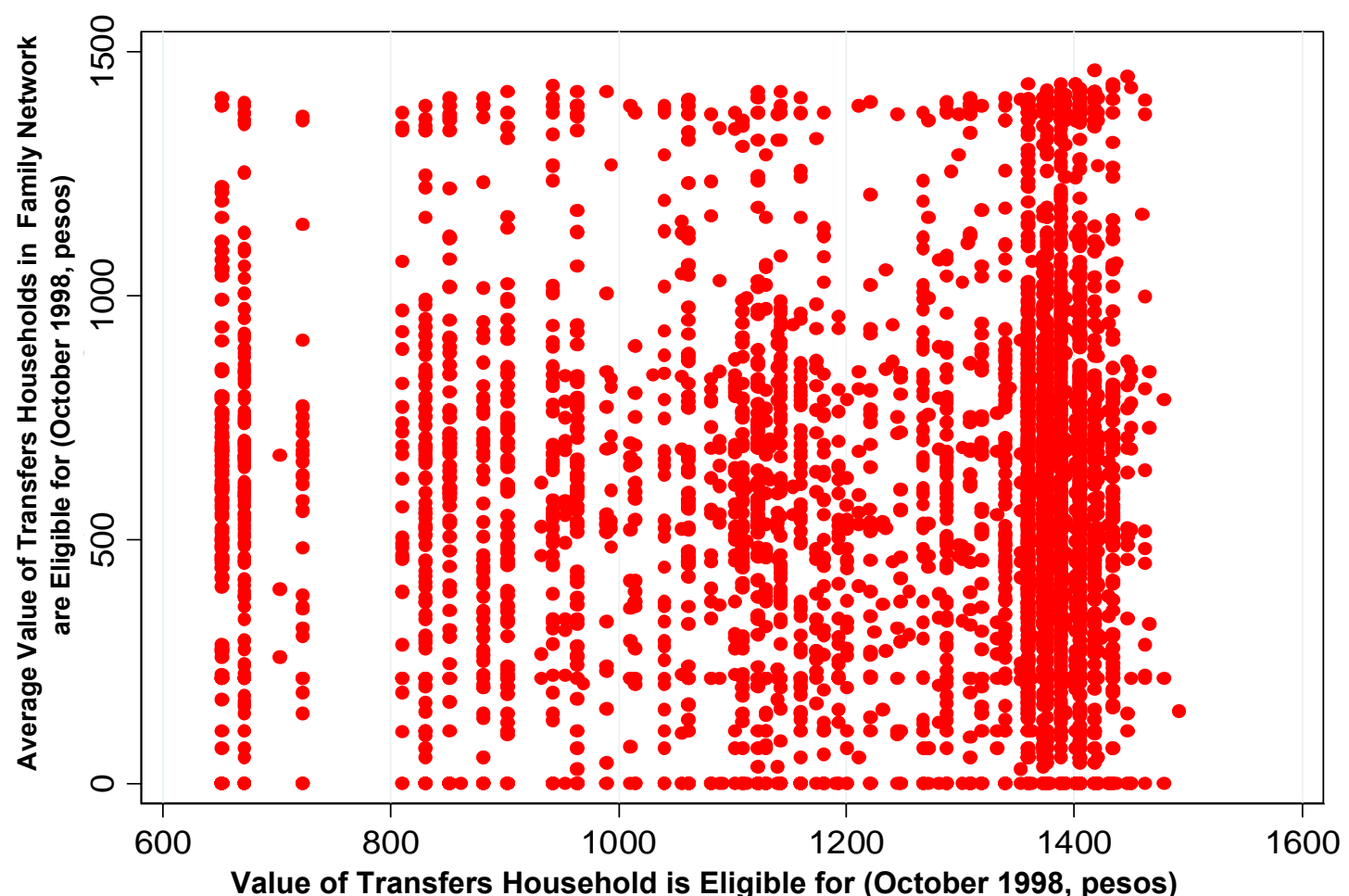

Notes: The samples for both figures are based on eligible couple headed households that can be tracked over the first and third Progresa waves. Figure $2 \mathrm{~A}$ plots the potential transfers each eligible connected household with secondary school aged children may receive, as recorded in October 1998, split for isolated and connected households. Figure 2B plots the potential transfers each eligible connected household with secondary school aged children may receive against the average potential transfer eligible households in its family network of degree 1, are entitled to, as recorded in October 1998. The correlation between these two potential sources of income for connected households is -.01. 